STRUCTURAL SCIENCE CRYSTAL ENGINEERING MATERIALS

ISSN 2052-5206

Received 8 September 2018

Accepted 18 October 2018

Edited by J. Lipkowski, Polish Academy of Sciences, Poland

Keywords: organic minerals; crystal engineering; metal-organic frameworks; MOFs; coordination polymers; hydrogen bonds; cocrystals.

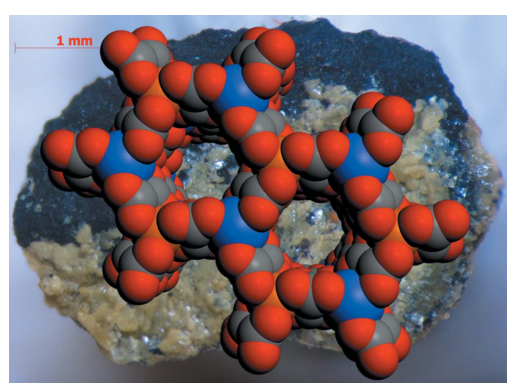

C 2018 International Union of Crystallography

\section{Understanding geology through crystal engineering: coordination complexes, coordination polymers and metal-organic frameworks as minerals}

\author{
Igor Huskić and Tomislav Friščić*
}

Department of Chemistry, McGill University, 801 Sherbrooke Street W., Montreal QC H3A 0B8, Canada *Correspondence e-mail: tomislav.friscic@mcgill.ca

Recent structural studies of organic minerals, coupled with the intense search for new carbon-containing mineral species, have revealed naturally occurring structures analogous to those of advanced materials, such as coordination polymers and even open metal-organic frameworks exhibiting nanometre-sized channels. While classifying such 'non-conventional' minerals represents a challenge to usual mineral definitions, which focus largely on inorganic structures, this overview highlights the striking similarity of organic minerals to artificial organic and metal-organic materials, and shows how they can be classified using the principles of coordination chemistry and crystal engineering.

\section{Introduction}

At present, mineralogy and chemistry stand as somewhat related, but fully independent fields of study with separate terms, paradigms and jargon. There is no doubt that the development of chemistry and materials science is intertwined with that of mineralogy and crystallography (Molčanov \& Stilinović, 2014). However, there is a tendency to perceive this relationship as exclusively a historical one; a scenario in which contemporary versions of each of these areas, following a period of brief historical entanglement, pursue their own independent development. Current mineralogy retains a strong focus on inorganic substances, typically based on strong ionic or covalent forces, where carbon is present exclusively in the form of carbonate species. In contrast, materials chemistry, and in particular the still very young area of crystal engineering (Desiraju, 2013), has veered towards 'soft matter': materials based on principles of supramolecular chemistry and molecular self-assembly via weaker, often readily reversible interactions, such as coordination bonds (Zhou et al., 2012), hydrogen (Steiner, 2002) or halogen (Cavallo et al., 2016) bonds or other non-covalent interactions (Brammer, 2017). There appears to be very little or no resemblance in composition or properties between conventionally encountered minerals, and different classes of recently emerged advanced materials, such as metal-organic frameworks (MOFs) (Cui et al., 2016), covalent organic frameworks (COFs) (Waller et al., 2015), pharmaceutical cocrystals (Delori et al., 2012; Duggirala et al., 2016) etc. Although framework topologies of minerals continue to serve as an inspiration for the design of MOFs, an effort that might be called 'mineralomimetic chemistry' (Fig. 1) (Kitagawa et al., 2004; Iwamoto et al., 1997), there is little similarity between the mineral archetypes and the corresponding MOFs. For example, the recently commercialized 
sodalite-topology (SOD-topology) zeolitic imidazolate framework ZIF-8 (Park et al., 2006), with composition $\mathrm{C}_{8} \mathrm{H}_{10} \mathrm{~N}_{2} \mathrm{Zn}$ and a surface area of almost $2000 \mathrm{~m}^{2} \mathrm{~g}^{-1}$, has little in common with its mineral archetype sodalite, $\mathrm{Na}_{8}$ $\left(\mathrm{Al}_{6} \mathrm{Si}_{6} \mathrm{O}_{24}\right) \mathrm{Cl}_{2}$ (Breck, 1973).

Here, we highlight a different perspective, based on the growing number of studies of very recently discovered or, in some cases, long known but only recently structurally characterized organic minerals: mineral species involving carbonbased molecular or ionic components that are not carbonates (Echigo \& Kimata, 2010). Only a handful of organic minerals are currently known, which includes organic molecular crystals, as well as their metal derivatives (Piro et al., 2016). The elucidation of their structures has revealed the geological occurrences of complex molecules previously thought to be limited to biological systems or synthetic organic laboratories, as well as of direct analogs of advanced functional metalorganic materials, such as MOFs exhibiting nanometre-sized channels, (Huskić, Pekov et al., 2016) and proton conductors with conductivities close to that of Nafion (Yamada et al., 2009). Moreover, increasing understanding of chemical compositions of other planets in the solar system has recently led to proposals that organic cocrystals, a class of multicomponent organic crystalline materials developed for their advanced pharmaceutical (Shan et al., 2014; Vishweshwar et al., 2006;), optical (Etter, 1990; Bushuyev et al., 2014) and reactive (Bučar \& MacGillivray, 2007) properties, could play a role in the geology of other planetary systems, such as Titan or Saturn (Maynard-Casely et al., 2016; Moore et al., 2016). All of these recent developments make a compelling case for the continuing connection between the cutting-edge developments in current materials chemistry and contemporary mineralogy.

Moreover, although organic minerals often contain metal ions, they cannot be correctly described using ionic lattice models that are regularly used to describe structures of other, inorganic, mineral types. Instead, we will show that structures of organic minerals are perfectly and intuitively described using the more recent concepts of coordination chemistry, supramolecular chemistry and crystal engineering. Conse- quently, we believe that contemporary materials science and mineralogy not only demonstrate a close relationship, but that the two fields can still readily inform and advance each other. Observing and understanding the appearance of complex organic and metal-organic structures in geological environments not only provides hints for future design of advanced functional materials, but also provides important insight into the compatibility and the overall lifecycle of such materials in a natural environment (Julien et al., 2017). Conversely, the classification and understanding of structures and properties of organic minerals will be greatly improved by embracing concepts of crystal engineering and coordination chemistry, such as coordination bonds, and supramolecular synthons.

Within the limited scope of this feature article we will attempt to highlight the close connection between mineralogy and crystal engineering and, by using selected examples, demonstrate that structures of organic minerals fall neatly into the established framework of organic and metal-organic materials science.

\subsection{Organic minerals}

During the bronze and iron ages, chemistry, metallurgy and mineralogy were indistinguishable fields of interest and focused mostly on mining and ore refining. In his work 'On Stones', the ancient Greek natural philosopher Theophrastus describes a large variety of minerals and precious gems, as well as reports on their physico-chemical properties based on techniques available at the time, such as heating, scratching etc. Not discriminating between organic and inorganic origin of minerals, Theophrastus' overview includes precious biomaterials, such as pearls, amber, fossilized organic matter (Caley \& Richards, 1956) as well as the now considered fictitious lyngurium, a mineral supposedly formed from solidified urine of a lynx. While lyngurium has been dismissed as a legend (Walton, 2001), it clearly illustrates the long-standing and close connection between mineralogy and biological matter. Indeed, there are many real examples of crystalline solids formed and actively used by living organisms. For example, urchin needles are porous, magnesium-enriched

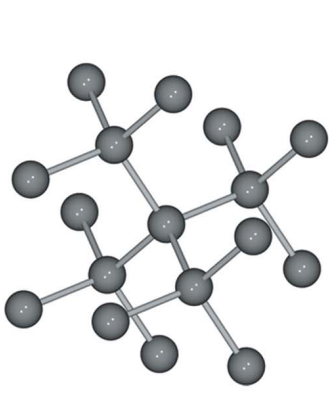

(a)

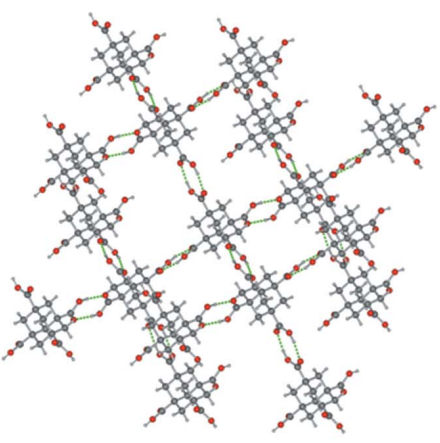

(b)

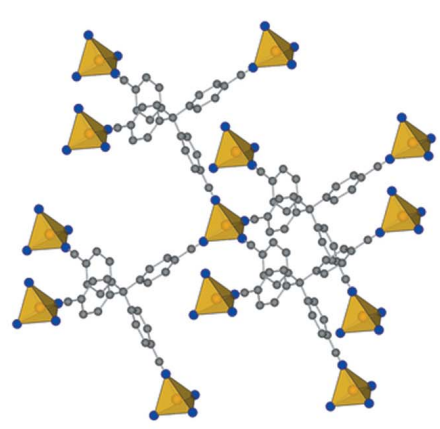

(c)

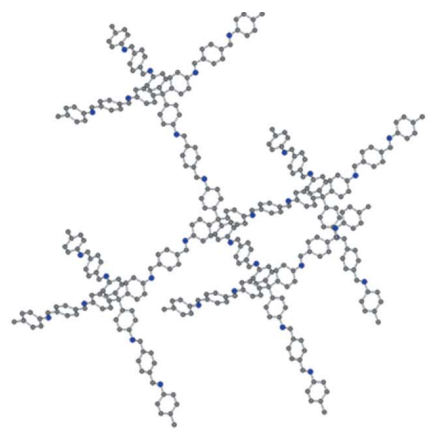

(d)

Figure 1

Fragments of crystal structures of different materials based on the same framework topology: $(a)$ mineral diamond; $(b)$ hydrogen-bonded framework in the twofold interpenetrated structure of adamantane-1,3,5,7-tetracarboxylic acid (CSD reference: GEJVEW; Ermer, 1988); (c) metal-organic framework $\left\{\mathrm{Cu}\left[\mathrm{C}\left(\mathrm{C}_{6} \mathrm{H}_{4} \mathrm{CN}\right)_{4}\right]\right\}_{n}^{n+}$, with anionic guests omitted for clarity (CSD reference: JARMEU; Hoskins \& Robson, 1989) and $(d)$ a covalent framework in the fivefold interpenetrated structure of COF-300 (CSD reference: XUGRAT; Uribe-Romo et al., 2009). 
single crystals of calcite (Su et al., 2000), while slug pedal mucous, exhibiting excellent lubrication and adhesion properties, is in fact a liquid crystal (Denny \& Gosline, 1980), as is partially dried giraffe saliva (Viney, 1999). Such examples remind us that nature cares little for our artificial division of naturally occurring materials into organic and inorganic domains. Currently, the International Mineralogical Association (IMA) recognizes about 5300 different mineral species. Out of these, only around $1 \%$ are organic minerals: recognized mineral species which contain 'organic' carbon, i.e. contain carbon species that are not carbonates or hydrogencarbonates (IMA list of minerals, August 2018). In contrast to other mineral types, the exact classification and definition of organic minerals appears to be a confusing, sometimes debated topic in contemporary mineralogy (Skinner, 2005). The classification of organic minerals has often been updated to reflect the newest discoveries and advances (Gaines et al., 1997; Nickel, 1995; Mills et al., 2009). Adding to the relative obscurity of organic minerals is their scarcity, which means that most nonofficial resources, often including dictionaries and encyclopaedias, wrongly consider minerals to be exclusively inorganic crystalline naturally occurring materials (Merriam-Webster: https://www.merriam-webster.com/dictionary/mineral; The Free Dictionary: https://www.thefreedictionary.com/mineral). However, the IMA Commission on New Minerals and Mineral Names (CNMMN) defines a mineral to be an element or a chemical compound that is normally crystalline and that has been formed by geological processes. This definition, which is followed throughout this text, does not limit minerals to inorganic substances only. Furthermore, according to the CNMMN criteria, anthropogenic materials and materials formed by the action of geological processes on anthropogenic substances, other than anthropogenic minerals grandfathered into current mineral classifications, should not be considered minerals. Similarly, substances originating from a biological process (biogenic substances), such as oxalate-based crystalline materials in plants, or marine mollusc shells, are also not considered minerals. However, if such carbon-containing substances have subsequently participated in geological processes, and were involved in the genesis of a crystalline compound, then such a product can be considered a mineral (Nickel, 1995). Indeed, whereas some of the organic minerals are purely organic compounds (e.g. acetamide, uric acid in uricite), many contain a wide range of metal ions, including not only well known biologically essential metals such as calcium, magnesium, copper or iron, but also other transitional metals (e.g. Al, Y), lanthanides and actinides (e.g. Ce, $\mathrm{U})$, that are not of biogenic nature (Echigo \& Kimata, 2010). The abundance of such non-biogenic metals is a clear indication that the corresponding organic minerals have not been excreted by a living organism but were formed from organic matter that has participated in geological processes which alter the geochemical composition of the Earth's crust. It is also important to note that the CNMMN recommendation does not exclude amorphous substances, providing they can be sufficiently characterized and unequivocally recognized - such as, for example, amber (Anderson et al., 1992).
Besides the structural beauty of organic minerals, an important inspiration for this feature article is the difficulty that the usual approaches of mineral classification experience when dealing with organic minerals. Both the Dana (Gaines et al., 1997) and the Nickel-Strunz (Mills et al., 2009) systems recognize organic minerals as one of the mineral subclasses. The Nickel-Strunz approach subdivides organic minerals into salts of organic acids (such as mellite, stepanovite, hoganite) and hydrocarbons (for example, idrialite, refikite). The Nickel-Strunz also permits for a third sub-division, including miscellaneous organic minerals that do not fit among the first two groups, exemplified by the geoporphyrin mineral abelsonite, or the small neutral molecule acetamide. The Dana classification does not even attempt a structural classification of diverse organic minerals.

With our background in chemistry and materials science, rather than geology and mineralogy, we believe that the difficulty of achieving a uniform, regular classification of organic minerals arises from the use of traditional approaches to chemical bonding (e.g. ionic versus covalent etc.) and compound classification (e.g. hydrocarbons, salts etc.). While they have certainly not been outdated, these traditional concepts have been greatly expanded over the past several decades by the rapid development of coordination chemistry (metal-organic chemistry), supramolecular chemistry and crystal engineering. Consequently, this contribution will address selected examples of organic minerals and demonstrate how their structures, which can be associated with traditional nomenclature of chemistry and mineralogy only with difficulty or not at all, can be readily and naturally classified using more recent concepts into coordination polymers, metal-organic frameworks and more.

\subsection{Crystal engineering}

Crystal engineering is, essentially, a practical utilization of concepts of supramolecular chemistry in solid-state and materials chemistry. It is primarily concerned with recognizing and understanding the different interactions between molecules and ions in crystalline materials, aiming to understand structure-property relationships and, eventually enable the rational design of crystalline materials with predictable properties. It is believed that the term crystal engineering was first used in the context of solid-state organic chemistry by Pepinsky in the 1950s (Desiraju, 2010), but the field began to be defined in the 1960s through the work of Schmidt, Etter (Schmidt, 1971; Etter et al., 1990) and subsequently Desiraju, Jones, Aakeroy and others (Desiraju, 2010; Aakeröy, 1997; Trask \& Jones, 2005; Foxman et al., 1998; MacGillivray et al., 2008). Central to crystal engineering is the analysis of the solid-state arrangement of molecules in terms of different types of molecular recognition motifs, such as hydrogen or halogen bonds, $\pi \cdots \pi$ stacking patterns, halogen $\cdots$ halogen interactions, auro- or argentophillic interactions, and more.

For directional supramolecular interactions such as hydrogen and halogen bonds, wherein the association between molecules takes place through a linear attachment between 
well defined donor and acceptor groups, graph-set analysis (Etter, 1990) permits structures to be precisely distinguished based on topology, size and structure. As another point of similarity between crystal engineering and mineral science, we note that such analysis vaguely resembles the approaches used to describe silicate structures (Liebau, 2003). In terms of topology, the motifs of supramolecular interactions in molecular crystals are divided into rings, chains or self-bonded structures, with respective descriptors $R, C$ and $S$. The sizes of $R$ - and $S$-motifs are defined by the number of constituent atoms. For the extended $C$-motifs, the size of the synthon is defined by the number of atoms in the smallest repeat unit, reminiscent of the nomenclature of chain silicates. The synthon size is usually given as a number in brackets, following the topology descriptor. Finally, the structure of a given $R, C$ or $S$ motif is determined by counting the number of hydrogen (or halogen) bond donors and acceptors, which are then written immediately next to the topology descriptor, in superscript and subscript format, respectively. The resulting combination of topology, size and structure descriptors provides a symbol which uniquely describes a supramolecular interaction motif. Examples of such graph-set symbols with corresponding molecular recognition motifs are given in Fig. 2.

Key to the development of crystal engineering, which today provides significant freedoms for the design of functional molecular, ionic and covalent crystals, is the realization that certain combinations of functional groups can reliably form very particular assembly motifs in the solid state. These robust motifs of supramolecular interactions, also known as supramolecular synthons, can be used to reliably assemble one, two, three or even more carefully designed, or judiciously chosen, types of molecules in a crystal. Examples of robust supramolecular synthons that play important roles in crystal engineering are the cyclic $R_{2}^{2}(8)$ homodimers of carboxylic acids and of amides (Friščić \& Jones, 2007), $R_{2}^{2}(7)$ heterodimers established between aromatic structures involving an $s p^{2}$ hybridized nitrogen atom, such as pyridines, imidazoles, triazoles etc, and carboxylic acids (Trask \& Jones, 2005; Shan et al., 2002; Childs \& Hardcastle, 2007). The $R_{2}^{2}(8)$ synthon is also of major significance in biological systems, as it underlies the assembly of adenine and thymine base pairs in DNA, as well as pairs of adenine and uracil in RNA structure (Fonseca Guerra et al., 2000). An example of a well known supramolecular synthon with an extended structure are the amide ladders' which consist of a combination of $C(4), R_{2}^{2}(8)$ and $R_{4}^{2}(8)$ motifs (Aakeröy et al., 2007). The power of crystal engineering is shown by reliable and high-yielding supramolecular synthesis of molecular cocrystals, crystalline solids based on two, three or more types of molecules (Aakeröy et al., 2001). In many cases, such control over molecular assembly leads to designer properties, such as reactivity to form discrete or polymeric products. Whereas the assembly of two-component crystals is today readily achieved by judicious choice of complementary functional groups on molecules, synthesizing cocrystals involving three or more components also requires consideration of other design principles, e.g. the relative strengths of acids and bases, or the use of mutually orthogonal interactions (Dubey et al., 2016; Topić \& Rissanen, 2016; Bhogala \& Nangia, 2008).

\subsection{Coordination polymers and metal-organic frameworks}

Coordination polymers are structures based on arrays of metal-ligand coordination bonds extending in one, two or three dimensions. Metal-organic frameworks (MOFs, also known as porous coordination polymers, coordination networks etc.) are a subset of coordination polymers based on two- or three-dimensional networks of coordination bonds (Batten et al., 2013, 2012; Öhrström, 2015). These materials, some of which have recently been commercialized, provide an impressive illustration of how complex and functional mate-

(a)

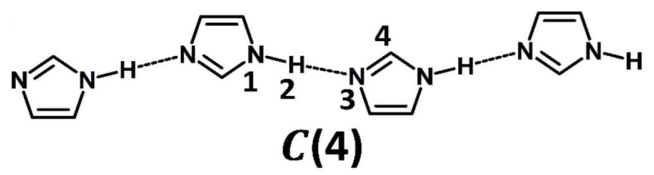

(b)
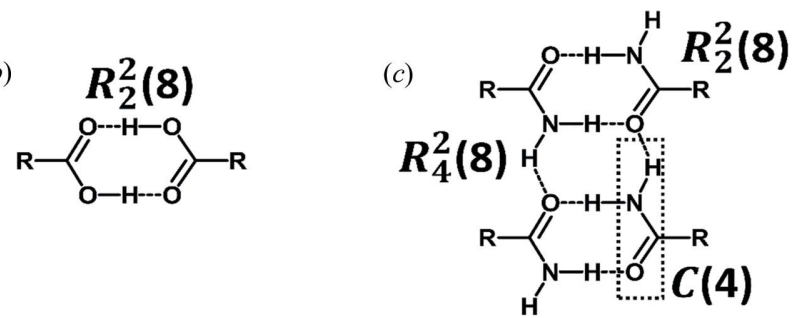

(d)

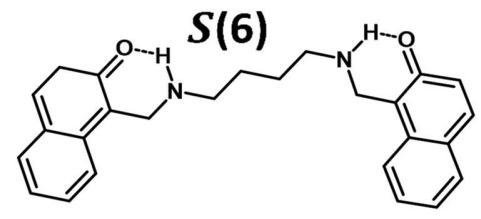

(e)

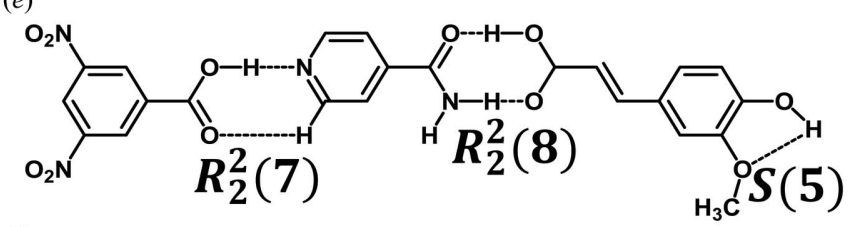

$(f)$

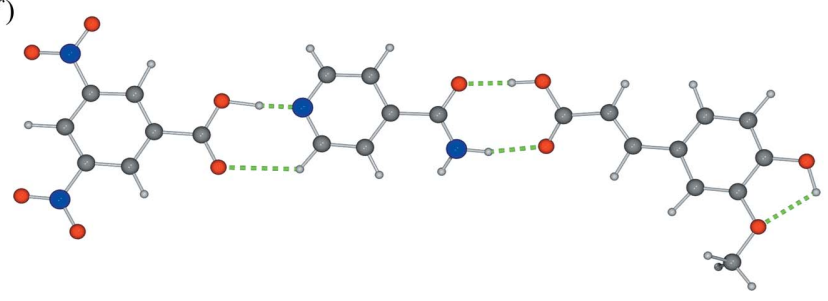

Figure 2

Examples of graph-set assignments: $(a)$ a zigzag $C(4)$ chain in the crystal structure of imidazole (Martinez-Carrera, 1966); $(b)$ a general $R_{2}^{2}(8)$ carboxylic acid homodimer synthon, found in a wide number of carboxylic acid crystal structures (Bučar et al., 2007); (c) fragment of a one-dimensional amide ladder synthon, composed of $C(4), R_{2}^{2}(8)$ and $R_{4}^{2}(8)$ synthons (Aakeröy et al., 2007); (d) $S(6)$ synthon based on an intramolecular hydrogen bond in a naphthalidimine Schiff base (Friščić et al., 1998); (e) a ternary molecular assembly designed by the Aakeröy group, displaying intermolecular $R_{2}^{2}(7)$ carboxylic acid-pyridine heterosynthon and an amide-carboxylic acid heterosynthon, along with an intramolecular $S(5)$ motif and $(f)$ a fragment of the crystal structure of the ternary molecular assembly designed by the Aakeröy group for comparison (CSD reference: BUFQAU; Aakeröy et al., 2001). 
rials can be designed by judicious choice of building blocks (Seth \& Matzger, 2017). The design of MOFs is based on the use of molecular- or atomic-sized nodes and linkers that exhibit both a rigid shape and a rigid binding geometry which, upon the formation of coordination bonds, leads to the formation of extended networks with regular, precisely controlled topologies. The design of different classes of MOFs was inspired by network topologies first observed in closepacked mineral structures (Wells, 1977; Moulton \& Zaworotko, 2001).The analysis of such mineral structures enabled the selection and design of metal-based nodes and organic linkers suitable for the synthesis of a metal-organic material exhibiting the same topology, but with a significantly larger fraction of guest-accessible space (Li et al., 2014). This nodeand-linker design has been well illustrated in Robson's pioneering demonstration of coordination network synthesis, wherein a wide open diamondoid topology (dia-topology) framework, inspired by topological analysis of diamond, was synthesized by using a tetrahedrally coordinated metal ion, such as the $d^{10}$-configuration $\mathrm{Cu}^{+}$or $\mathrm{Zn}^{2+}$, in combination with either a linear organic linker or another tetrahedral node equipped with suitable metal-binding ligand atoms (Hoskins \& Robson, 1989). Specifically, crystallization of copper(I) tetrafluoroborate $\left(\mathrm{Cu}^{+} \mathrm{BF}_{4}^{-}\right)$in the presence of tetrakis(4cyanophenyl)methane from nitrobenzene solution yielded the first reported example of a three-dimensional wide open framework held by coordination bonds. The choice of $\mathrm{CuBF}_{4}$ as the metal source was significant because other, less coordinatively inert, anions could potentially interfere with the node-and-linker self-assembly process. Whereas this prototype of a metal-organic framework was cationic and based on a single metal cation as a node, most recent designs for MOFs rely on more complex secondary building units (SBUs) (Eddaoudi et al., 2001) as nodes, and can be used to produce cationic (Ma et al., 2016), anionic (Alkordi et al., 2008), but in most cases, neutral structures (Rosi et al., 2003). The most common examples of SBUs are metal-organic clusters with rigid ligand-bonding geometries, such as the tetranuclear $\mathrm{Zn}_{4} \mathrm{O}$ carboxylate cluster with octahedral binding geometry (Doonan et al., 2009), the $\mathrm{Zr}_{6}(\mathrm{OH})_{4} \mathrm{O}_{4}$ cluster with carboxylate linkers connected along the vertices of a cuboctahedron (Gutov et al., 2014), or the binuclear 'paddlewheel' carboxylate clusters acting as octahedral nodes (Dybtsev, Chun \& Kim 2004).

Overall, the node-and-linker design of MOFs permits the bottom-up synthesis of open framework materials with regular channels or cavities whose diameters exceed $1 \mathrm{~nm}$, and that can exhibit very high microporosity upon evacuation. The latter is showed by Brunauer-Emmet-Teller (BET) surface areas approaching $10000 \mathrm{~m}^{2} \mathrm{~g}^{-1}$ for selected materials (Farha et al., 2012). However, the importance of MOFs lies not so much in the ability to access extreme levels of microporosity, but in their modular design which provides great freedom in the selection of MOF components. This is reflected in the isoreticular design of MOFs (Furukawa et al., 2011, 2008; Deng et al., 2012; Rungtaweevoranit et al., 2017), wherein building blocks of identical binding geometry are expected to reliably form frameworks of the same topology, regardless of their size or substitution pattern. Such modularity and reliability of molecular assembly processes leading to MOF formation is key to creation of materials that combine high porosity with one or more functional properties, such as catalysis (Lee et al., 2009), light-harvesting (Lee et al., 2011), conductivity (Sheberla et al., 2017) and more.

\subsection{The carbon mineral challenge}

Organic minerals are usually found on a single location and in quantities that are too meager to be economically relevant. Compared with the vast number of inorganic mineral species, the natural abundance and economic significance of organic minerals are often overlooked and considered to be of little interest beyond academic research. However, organic minerals can play an important role in helping to understand the geological and atmospheric history of Earth and, potentially, other planets. Ernstburkeite, a mineral found as micrometre-sized inclusions deep under the Antartic ice, provides an illustration of the potential importance of minerals containing organic molecules. This mineral is a naturally occurring form of magnesium methanesulfonate (Genceli Güner et al., 2010), a substance that would be more readily found in an organic synthetic laboratory than in a geological study (Fig. 3b). Importantly, ernstburkeite is, to date, a unique example of naturally occurring methanesulfonic acid, which is an important indicator of ice extent, marine productivity and climate change in the past (Genceli Güner $e t$ $a l ., 2013)$. The geological and atmospheric events in the history of the Earth have always had a strong impact on the biosphere which, in turn, has strongly influenced the planetary surface and atmosphere. Lichens, for example, are simple but longlived symbiotic organisms that have existed on Earth for at least 400 million years (Taylor et al., 1995). Certain species of lichens are known to grow on bare rock, surviving largely through photosynthesis, excreting lichen acids (Adamo \& Violante, 2000). The lichen acids are a diverse family of organic compounds, including complex molecules such as norstictic acid, as well as very simple compounds, such as oxalic acid (Chen et al., 2000). In many cases, lichen acids are utilized by organisms to access mineral nutrients from the bedrock beneath, or to precipitate out toxic metals, such as lead or tin (Purvis \& Halls, 1996). Lichens are highly sensitive to atmospheric change and have been used as reliable bioindicators of air quality, metal contamination and ozone depletion. Though short-lived on the geological scale, lichens and other organisms provide us with components of organic minerals and fossil fuels as records of Earth's evolution over thousands or even millions of years.

Consequently, while organic minerals are not frequently encountered, they provide important clues on Earth's history and, importantly, the biogeological cycle of carbon in nature. The increased interest in the origin and fate of different forms of carbon on Earth has recently sparked 'The Carbon Mineral Challenge' (CMC, see also https://www.mineralchallenge.net), an initiative dedicated to the discovery of new carbon- 
containing mineral species. This initiative, that has led to the discovery of 15 new carbon minerals since its inception in 2015 , was inspired by the work of a team of researchers based at the Carnegie Institute, Purdue University and the University of Arizona, who applied a statistical model known as 'Large Number of Statistical Events' (LNRE) to a database containing the 403 carbon-containing minerals known at the time (Hazen et al., 2016). This model predicted that at least an additional 145 carbon-bearing minerals should exist on Earth (Fig. 3). Of these, 129 would be expected to contain oxygen, 118 should contain hydrogen, with calcium and sodium expected to be found in at least 52 and over 60 minerals, respectively. These predicted mineral compositions included the natural forms of certain synthetic materials, such as

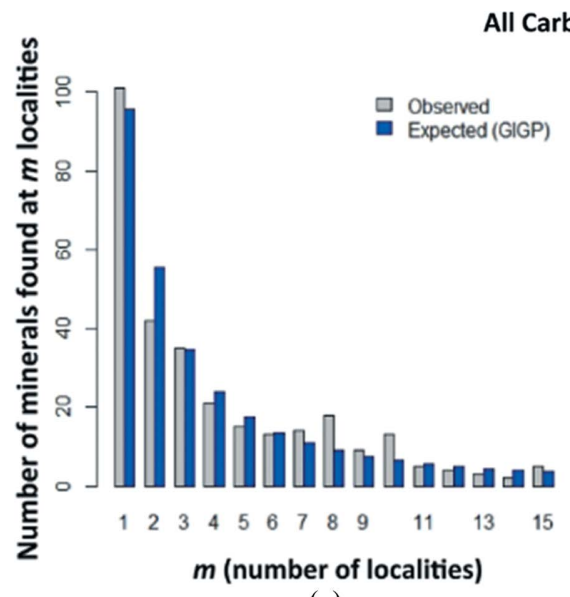

(a)

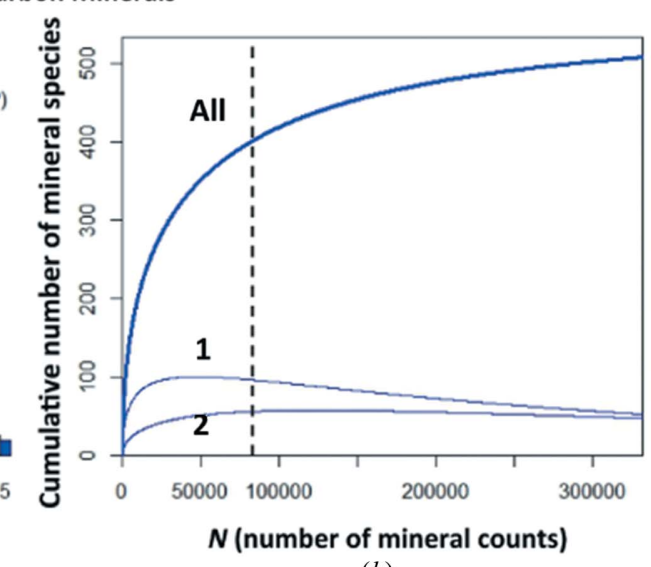

(b)
Figure 3

(a) Frequency spectrum analysis of 403 carbon-bearing minerals, with 82922 individual minerallocality data (from http://mindat.org as of January 2015). (b) Prediction of the mineral species accumulation curve (All), which plots the number of expected carbon mineral species ( $y$ axis) as additional mineral species/locality data ( $x$ axis) are discovered. The vertical dashed line indicates data recorded. Images taken with permission from Hazen et al. (2016).

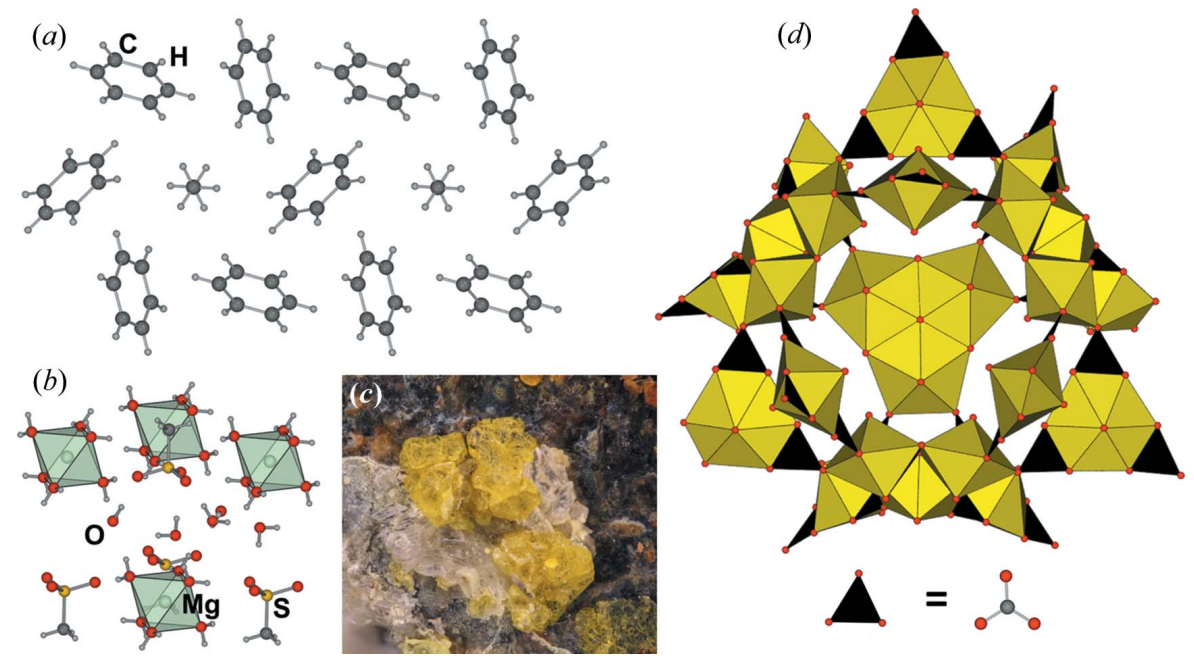

Figure 4

(a) Arrangement of molecules in the structure of the cocrystal of ethene and benzene, viewed along the crystallographic $c$ axis (CSD reference: UKACAM; Maynard-Casely et al., 2016). (b) Fragment of the crystal structure of magnesium methanesulfonate hexahydrate, a synthetic analog of ernstburkeite (CSD reference: ENEFOT; Genceli Güner et al., 2010). (c) A sample of ewingite (photo courtesy of Dr Travis Olds). (d) Polyhedral representation of an oxouranyl cage in the structure of ewingite (Olds et al., 2017). carbides and numerous oxalates, organic molecules such as metalloporphyrins and hydrocarbons, as well as analogs of known minerals. Polymorphs and allotropes were deliberately excluded from the study, instead focusing only on the chemical composition of the minerals. Curiously, no nitrogen-containing organic minerals have been included in this prediction, although a number of organic minerals containing this element exist (such as triazolite (Chukanov et al., 2018), acetamide (Srebrodolskii, 1975) or guanine (Unger, 1846). The CMC, inspired by this work, aims to shed light on important and unanswered questions, such as the likelihood of neighbor planets, the possible effect of carbon-containing minerals on the appearance and development of life on Earth, and the role of human society and technology in the evolution of mineral species. The researchers involved in the CMC initative suggest evaporated saline lakes, coal mine fires, and volcanic fumaroles as the most probable sites for the discovery of new carbon-containing minerals. Moreover, recent studies of the composition of other planetary objects in the solar system suggest that Saturn's moon Titan could host cocrystals as a type of organic mineral not yet encountered on Earth. Specifically, Maynard-Casely and co-workers have suggested that the surface of Titan could contain a cocrystal of ethane and benzene hydrocarbons (Fig. 4a) (MaynardCasely et al., 2016).

Some of the new carbon mineral species discovered since the beginning of the CMC project display remarkable inner ordering, which is reminiscent of highly advanced functional materials designed in laboratories. For example, triazolite is a mineral isolated from a guano deposit and exhibits a threedimensional framework structure consisting of triazolate and chloridebridged copper(II) ions, with hydrated $\mathrm{Na}^{+}$species occupying the channels of the structure. Interestingly, nitrogen is abundant in triazolite (Chukanov et al., 2018), although the statistical study that inspired the CMC did not consider the discovery of nitrogen-containing minerals. Ewingite, another mineral discovered within the scope of $\mathrm{CMC}$, has the chemical formula $\mathrm{Mg}_{8} \mathrm{Ca}_{8}$ $\left(\mathrm{UO}_{2}\right)_{24}\left(\mathrm{CO}_{3}\right)_{30} \mathrm{O}_{4}(\mathrm{OH})_{12} \cdot 138 \mathrm{H}_{2} \mathrm{O}$ and holds for the most structurally complex mineral with the information content (Krivovichev, 2013) of 12684.86 bits 
Table 1

Crystallographic parameters of organic minerals discussed in this work.

\begin{tabular}{|c|c|c|c|c|c|c|c|c|}
\hline Name & Composition & Space group & $a(\AA)$ & $b(\AA)$ & $c(\AA)$ & $\alpha\left(^{\circ}\right)$ & $\beta\left(^{\circ}\right)$ & $\gamma\left({ }^{\circ}\right)$ \\
\hline Triazolite & $\mathrm{NaCu}_{2}\left(\mathrm{~N}_{3} \mathrm{C}_{2} \mathrm{H}_{2}\left(\mathrm{NH}_{3}\right)_{2} \mathrm{Cl}_{3} \cdot 4 \mathrm{H}_{2} \mathrm{O}\right.$ & $P 2_{1} 2_{1} 2_{1}$ & $19.3575(5)$ & $7.1572(2)$ & $12.5020(4)$ & 90 & 90 & 90 \\
\hline Chanabayaite & $\mathrm{CuCl}\left(\mathrm{N}_{3} \mathrm{C}_{2} \mathrm{H}_{2}\right)\left(\mathrm{NH}_{3}\right) \cdot 0.25 \mathrm{H}_{2} \mathrm{O}$ & Imma & $19.484(3)$ & $7.2136(10)$ & $11.999(4)$ & 90 & 90 & 90 \\
\hline Abelsonite & $\mathrm{Ni}\left(\mathrm{C}_{31} \mathrm{H}_{32} \mathrm{~N}_{4}\right)$ & $P \overline{1}$ & $8.4416(5)$ & $10.892(7)$ & $7.275(4)$ & $90.465(2)$ & $113.158(2)$ & $78.080(2)$ \\
\hline Stepanovite & $\mathrm{NaMgFe}\left(\mathrm{C}_{2} \mathrm{O}_{4}\right)_{3} \cdot 9 \mathrm{H}_{2} \mathrm{O}$ & $R 3 c$ & 9.28 & 9.28 & 36.67 & 90 & 90 & 120 \\
\hline Zhemchuzhnikovite & $\mathrm{NaMgAl}_{x} \mathrm{Fe}_{1-x}\left(\mathrm{C}_{2} \mathrm{O}_{4}\right)_{3} \cdot 9 \mathrm{H}_{2} \mathrm{O}$ & $P 3 c$ & 16.7 & 16.7 & 12.5 & 90 & 90 & 120 \\
\hline Humboldtine & $\mathrm{Fe}\left(\mathrm{C}_{2} \mathrm{O}_{4}\right) \cdot 2 \mathrm{H}_{2} \mathrm{O}$ & $C 2 / c$ & $12.011(11)$ & $5.557(5)$ & $9.920(9)$ & 90 & $128.53(3)$ & 90 \\
\hline Deveroite & $\mathrm{Ce}_{2}\left(\mathrm{C}_{2} \mathrm{O}_{4}\right)_{3} \cdot 10 \mathrm{H}_{2} \mathrm{O}$ & $P 2_{1} / c$ & $11.240(8)$ & $9.635(11)$ & $10.339(12)$ & 90 & $114.41(10)$ & 90 \\
\hline Levinsonite & $(\mathrm{Y}, \mathrm{Nd}, \mathrm{La}) \mathrm{Al}\left(\mathrm{C}_{2} \mathrm{O}_{4}\right)\left(\mathrm{SO}_{4}\right)_{2} \cdot 12 \mathrm{H}_{2} \mathrm{O}$ & $P 2 / n$ & $10.289(1)$ & $9.234(1)$ & 11.015 & 90 & 108.50 & 90 \\
\hline Zugshunstite & $(\mathrm{Ce}, \mathrm{Nd}, \mathrm{La}) \mathrm{Al}\left(\mathrm{C}_{2} \mathrm{O}_{4}\right)\left(\mathrm{SO}_{4}\right)_{2} \cdot 12 \mathrm{H}_{2} \mathrm{O}$ & $C 2 / c$ & 8.718 & 18.313 & 13.128 & 90 & 93.9 & 90 \\
\hline Joanneumite & $\mathrm{Cu}\left(\mathrm{C}_{3} \mathrm{~N}_{3} \mathrm{O}_{3} \mathrm{H}_{2}\right)_{2}\left(\mathrm{NH}_{3}\right)_{2}$ & $P \overline{1}$ & $5.042(1)$ & $6.997(1)$ & $9.099(2)$ & $90.05(3)$ & $98.11(2)$ & $110.95(3)$ \\
\hline Uricite & $\mathrm{C}_{5} \mathrm{H}_{4} \mathrm{~N}_{4} \mathrm{O}_{3}$ & $P 2_{1} / a$ & $14.464(3)$ & $7.403(2)$ & $6.208(1)$ & 90 & $65.10(5)$ & 90 \\
\hline Tinnunculite & $\mathrm{C}_{5} \mathrm{H}_{4} \mathrm{~N}_{4} \mathrm{O}_{3} \cdot 2 \mathrm{H}_{2} \mathrm{O}$ & $P 2_{1} / c$ & $7.261(9)$ & $6.365(7)$ & $17.48(3)$ & 90 & $91.0(1)$ & 90 \\
\hline Formicaite & $\mathrm{Ca}(\mathrm{HCOO})_{2}$ & $P 4_{1} 2_{1} 2$ & $6.765(2)$ & $6.765(2)$ & $9.456(3)$ & 90 & 90 & 90 \\
\hline Dashkovaite & $\mathrm{Mg}(\mathrm{HCOO})_{2} \cdot 2 \mathrm{H}_{2} \mathrm{O}$ & $P 2_{1} / c$ & $8.64(1)$ & $7.15(1)$ & $9.38(1)$ & 90 & 98 & 90 \\
\hline Mellite & $\mathrm{Al}_{2}\left[\mathrm{C}_{6}(\mathrm{COO})_{6}\right] \cdot 16 \mathrm{H}_{2} \mathrm{O}$ & $I 4_{1} /$ acd & 15.53 & 15.53 & 23.19 & 90 & 90 & 90 \\
\hline Hoganite & $\mathrm{Cu}\left(\mathrm{CH}_{3} \mathrm{COO}\right)_{2} \cdot \mathrm{H}_{2} \mathrm{O}$ & $C 2 / c$ & 13.845 & 8.528 & 13.197 & 90 & $117.08(3)$ & 90 \\
\hline Paceite & $\mathrm{CaCu}\left(\mathrm{CH}_{3} \mathrm{COO}\right)_{4} \cdot 6 \mathrm{H}_{2} \mathrm{O}$ & $I 4 / m$ & 11.155 & 11.155 & 16.236 & 90 & 90 & 90 \\
\hline
\end{tabular}

per unit cell. It also boasts the largest (natural) structural cluster of any mineral discovered to date, containing 24 uranium atoms (Figs. $4 c$ and $4 d$ ). Many of the organic minerals exhibit recognizable structural motifs found in crystal engineering and MOF design. Here we describe some of these mineral species (Table 1), their structural analogs and the interesting connection between nature, geochemistry and crystal engineering.

\section{Abelsonite}

Abelsonite is a unique example of a geoporphyrin - a mineral containing the complex porphyrin moiety. Specifically, it is a nickel(II) complex of the elaborate desoxophylloerythroetioporphyrin (Fig. 5a), proposed to originate from decaying plant matter containing chlorophyll, a naturally occurring porphyrin (Treibs, 1935). The mineral, named after P. H. Abelson, the former President of the Carnegie Institution of Washington and a pioneer of organic geochemistry, was first discovered in the Uintah county (Utah, USA). The mineral was first observed in the Mahogany Zone oil shale of the Green River Formation as 'occasional fine pink-purple metallic patches' within core sample depths ranging from 45 to 2500 feet. The molecular structure of abelsonite was first determined by Storm and co-workers using proton nuclear magnetic resonance (NMR) spectroscopy (Storm et al., 1984), and the crystal structure was determined only recently by Hummer et al. (2017). Incidentally, abelsonite is possibly the first mineral whose structure was determined by NMR, a technique becoming ever more important in mineralogy (Ashbrook \& Dawson, 2016). As could be inferred from the described physical appearance and properties of abelsonite, the porphyrin moieties in its crystal structure form stacks in a slightly offset face-to-face fashion (Fig. 5b). Besides the central nitrogen groups that are already engaged in chelating the $\mathrm{Ni}^{\mathrm{II}}$ center, the desoxophylloerythroetioporphyrin lacks any groups on its periphery capable of forming hydrogen bonds or additional coordination metal-ligand bonds. Consequently, the overall arrangement of the molecules in the crystal is dominated by weak intermolecular dispersion forces,

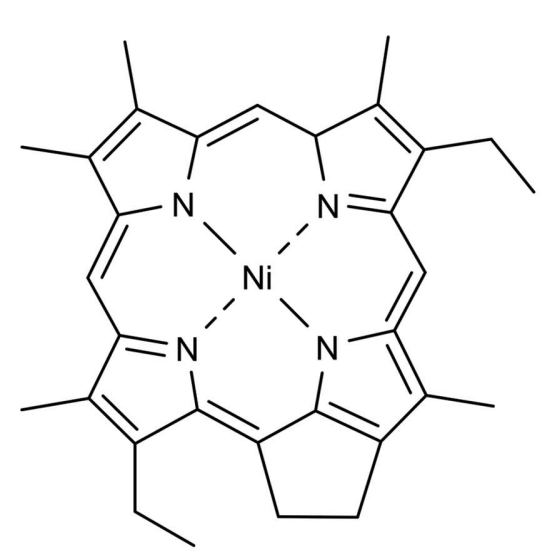

(a)

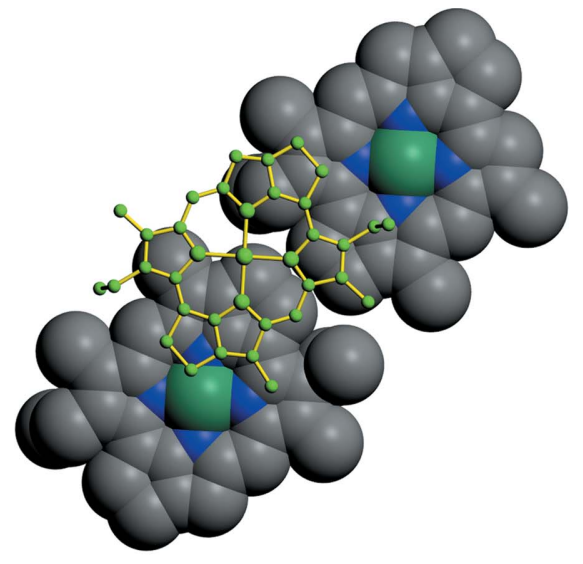

(b)

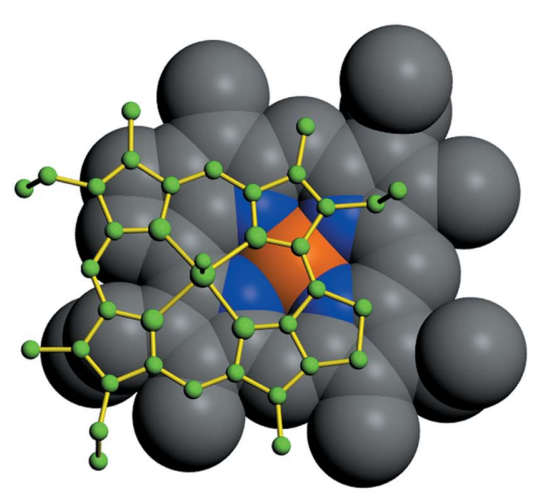

(c)

Figure 5

(a) Skeletal formula of nickel(II) desoxophylloerythroetioporphyrin. Stacking of molecules in the crystal structure of (b) abelsonite (CSD reference: ABELSO; Hummer et al., 2017) and (c) vanadyl desoxophylloerythroetioporphyrin (CSD reference: CAKMAC10; Ekstrom et al., 1983). For clarity, molecules in the lower layer are shown using the space-filling model. 
in contrast to artificial porphyrin systems that can be designed to assemble into pre-defined crystal structures through a variety of interactions (Titi et al., 2016; Goldberg, 2000, 2005). Consequently, the best description of abelsonite would be as a molecular crystal, rather than, for example, a salt. Whereas abelsonite is the only known example of a porphyrin mineral, other metallated and non-metallated porphyrin species have been isolated from crude oil, and structurally characterized by X-ray crystallography, NMR spectroscopy and mass spectrometry, but have never been observed in solid mineral form. One example is the vanadyl desoxophylloerythroetioporphyrin (CSD reference: CAKMAC10) (Ekstrom et al., 1983; Pettersen, 1984), which has been isolated from an Australian shale oil deposit. This compound has been crystallized as a chloroform solvate and its structure determined from single-crystal X-ray data. Compared with the porphyrin system in abelsonite, which stacks in an offset fashion, the molecules of the vanadyl variant form more extensive $\pi-\pi$ stacking (Fig. 5c). This vanadyl complex, and other petroporphyrins, are possible candidates for the discovery of new, molecularly complex, carbon minerals.

As already noted, the porphyrin molecular backbone is of significance in the context of crystal engineering of functional materials, due to its structural rigidity and ability to include coordinatively unsaturated metal centers (i.e. open metal centers). The importance of porphyrin rigidity for crystal structure design is noted in the work of the Robson group (Abrahams et al., 1994), who described the combination of a square-planar functionalized meso-tetrapyridyl-metalloporphyrin with tetrahedrally coordinated $\mathrm{Cu}^{\mathrm{I}}$ ions to deliberately form a framework with a platinum(II) sulfide topology (ptstopology) and large $(\sim 10 \AA)$ solvent-occupied pores. The importance of open metal sites introduced to crystal structures through metallated porphyrin moieties has been illustrated by Meng et al. (2012) using a porphyrin-based fcu-topology microporous MOF which effectively catalyzes the epoxidation of trans-stilbene due to a high density of active cobalt(II) sites embedded in porphyrin units.

\section{Oxalate minerals}

The largest group of presently known organic minerals are metal oxalates (Echigo \& Kimata, 2010), partly due to the natural abundance of oxalic acid but also the low solubility of most oxalates. Oxalic acid $\left(\mathrm{H}_{2} \mathrm{C}_{2} \mathrm{O}_{4}\right)$ is the simplest dicarboxylic acid, and with $\mathrm{p} K_{\mathrm{a}}$ values of 1.25 and 4.14 (Sillén et al., 1964 ) it is stronger than most naturally occurring organic acids. It is present as a product or by-product in the metabolism of a large number of organisms, including bacteria and fungi (Gadd, 1999, 2010). Many plants and lichens will produce oxalic acid and its salts as a part of defense mechanisms against biological (e.g. predators, microorganisms) or chemical (e.g. heavy metal ions in soil) dangers (Purvis \& Halls, 1996). An example of biological matter rich in oxalic acid are spinach leaves, containing $c a .1 \%$ of the compound by weight. Upon decay of such plant material, oxalic acid may react with surrounding environment, resulting in neogenesis of organic minerals. Often simply described as salts, such metal oxalates usually display extended structures based on metal-ligand coordination bonds and should, therefore, be classified as coordination polymers or MOFs. Many oxalate minerals represent different hydration states of a coordination polymer, as exemplified by calcium oxalate, $\mathrm{CaC}_{2} \mathrm{O}_{4}$, whose monohydrate appears as the mineral whewellite, the dihydrate as the mineral weddellite (Tazzoli \& Domeneghatti, 1980) and the trihydrate corresponds to the mineral caoxite (Basso et al., 1997). Other oxalate minerals contain other metals such as copper [moolooite, wheatleyite; Chisholm et al. (1987)], manganese [lindbergite; Atencio et al. (2004)], iron [minguzzite, humboldtine; Piro \& Baran (2018), Echigo \& Kimata (2008)] and rare earths [zugshunstite, levinsonite; Rouse et al. (2001)]. Of these, humboldtine is a spectacular example of a naturally abundant advanced material, as synthetic samples were shown to exhibit excellent proton-conductive properties.

\subsection{Humboldtine - a proton-conducting coordination polymer}

Humboldtine is a naturally occurring coordination polymer with the composition $\mathrm{FeC}_{2} \mathrm{O}_{4} \cdot 2 \mathrm{H}_{2} \mathrm{O}$ and consists of linear chains of octahedrally coordinated iron(II) ions bridged by oxalate ligands and coordinated by water molecules in axial positions (Fig. 6) (Echigo \& Kimata, 2008). While the mineral, which is found as a by-product of lichen growth on ironbearing rock, has been known since at least 19th century (Leonhard, 1826), it was only in 2009 that its excellent protonconduction properties were noted by the Kitagawa group (Yamada et al., 2009). With a conductivity of $1.3 \mathrm{mS} \mathrm{cm}^{-1}$ at $25^{\circ} \mathrm{C}$ and $98 \%$ relative humidity, humboldtine is among the most efficient crystalline metal-organic proton conductors, comparable to Nafion ${ }^{\mathbf{1}}$ and many other state-of-the-art proton conductors.

\subsection{Stepanovite and zhemchuzhnikovite - naturally occur- ring MOFs}

Stepanovite and zhemchuzhnikovite are the first observed examples of open MOF materials occurring in nature as minerals (Huskić \& Friščić, 2015). They are rare minerals that were first discovered in 1942 and 1963, respectively, in the Chai-Tumus region of the Lena river estuary of Siberia, in a coal seam approximately $200 \mathrm{~m}$ below the permafrost surface (Knipovich et al., 1963). A detailed analysis provided the sketches (Figs. $7 a$ and $7 b$ ) of the crystal habits, chemical composition and crystallographic unit-cell parameters obtained through X-ray powder crystallography, but their crystal structures at the time remained unknown. In 2016, single-crystal X-ray diffraction experiments on synthetic and natural stepanovite and zhemchuzhnikovite samples (Figs. $7 a$ and $7 c$ ) revealed two-dimensional sheets in which octahedrally coordinated sodium and iron(III) ions are bridged by oxalate ligands to form open, anionic nets of hexagonal $(3,6)$-topology

\footnotetext{
${ }^{\mathbf{1}}$ Nafion 117 conductivities were measured to be between 1 and $100 \mathrm{mS} \mathrm{cm}^{-1}$ at high humidity, but are strongly dependent on temperature, form and pretreatment of Nafion (Sone, 1996).
} 
[honeycomb, hcb-topology], also seen in synthetic metal oxalate MOFs (Figs. 7d-7f). The charge of anionic sheets is compensated for by hexaaquamagnesium ions, $\mathrm{Mg}\left(\mathrm{H}_{2} \mathrm{O}\right)_{6}{ }^{2+}$, located in the openings of each sheet. The sheets are separated by layers of interstitial water molecules that are extensively hydrogen-bonded to oxalate linkers and $\mathrm{Mg}\left(\mathrm{H}_{2} \mathrm{O}\right)_{6}{ }^{2+}$ guests in each sheet. In stepanovite, the sheets stack in an offset $A B C A^{\prime} B^{\prime} C^{\prime}$ pattern, where $\mathrm{A}^{\prime}, B^{\prime}$ and $C^{\prime}$ represent layers rotated by $180^{\circ}$ around the vertical axis (Fig. $7 \mathrm{~g}$ ). In zhemchuzhnikovite, where about $60 \%$ of $\mathrm{Fe}^{\mathrm{III}}$ ions are isomorphously replaced by $\mathrm{Al}^{3+}$, crystal structure determination revealed the presence of identical sheets. However, the layers in zhemchuzhnikovite stack differently than in stepanovite, as

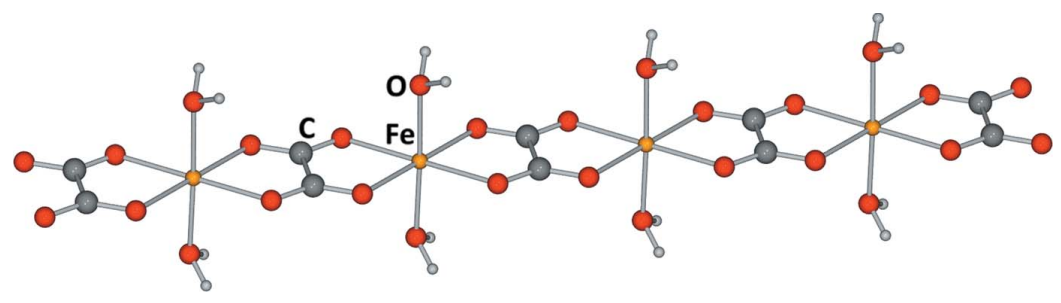

Figure 6

A fragment of a single one-dimensional coordination polymer chain in the crystal structure of humboldtine, iron(II) oxalate dihydrate (CSD reference: OXALFE; Echigo \& Kimata, 2008).
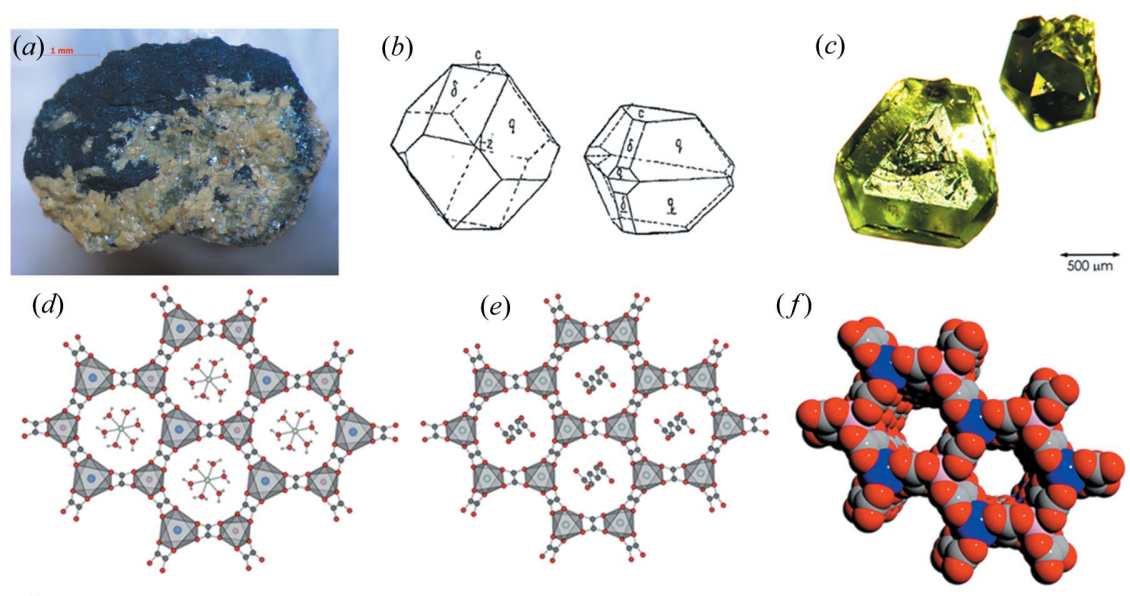

$(g)$

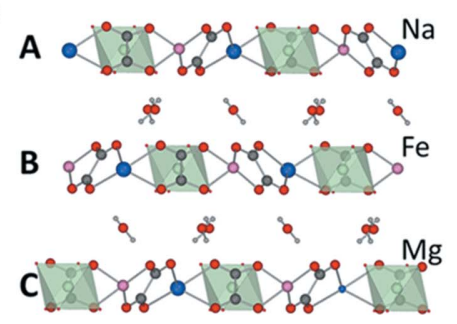

(h)

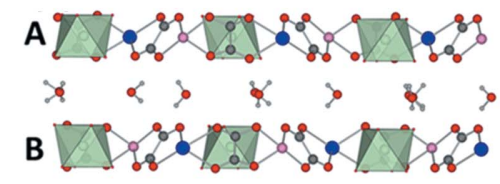

Figure 7

(a) A sample of stepanovite from the Chai-Tumus coal deposit (Sakha-Yakutia, Siberia, Russia; collection of E. I. Nefedov). (b) Crystal habit of stepanovite crystals reported by Knipovich et al. (1963). (c) Crystals of the synthetic analog of stepanovite. (d) A single hcb-topology layer in the structures of stepanovite or zhemchuzhnikovite (CSD references: OKUTUL02 and IRUYEB, respectively; Huskić et al., 2016) with $\mathrm{Mg}\left(\mathrm{H}_{2} \mathrm{O}\right)_{6}{ }^{2+}$ ions occupying framework pores. (e) A proton-conducting zinc oxalate MOF reported by the Kitagawa group, with adipic acid threaded through channels (CSD reference VUKXUV; Sadakiyo et al., 2009). ( $f$ ) Stereographic projection of the stacking of layers in the structure of zhemchuzhnikovite, forming channels, with $\mathrm{Mg}\left(\mathrm{H}_{2} \mathrm{O}\right)_{6}{ }^{2+}$ guests omitted for clarity. View along the $a b$ plane of the crystal structure of: $(g)$ stepanovite, illustrating the stacking of layers in an $A B C A^{\prime} B^{\prime} C^{\prime}$ pattern and $(h)$ zhemchuzhnikovite, illustrating the stacking of layers in an $A B$ fashion. they follow a much simpler $A B$ repeat pattern. Unlike stepanovite, the pores of adjacent layers in zhemchuzhnikoare aligned, yielding channels filled with $\mathrm{Mg}\left(\mathrm{H}_{2} \mathrm{O}\right)_{6}{ }^{2+}$ samples (Huskić, Pekov et al., 2016; Piro et al., 2016).

Whereas the structures of two-dimensional metal-organic explored in the 1990s by the Decurtins group (Decurtins et al., 1994) in the development of metal-organic magnetic materials and, more recently, by the Kitagawa group in the design of proton-conductive MOFs (Fig. 7e) (Sadakiyo et al., 2014, 2016). Consequently, it is possible that the studies conducted on this type of MOF since the 1990s can provide insight into the formation and properties of stepanovite and zhemchuzhnikovite. Specifically, the pioneering work of Descurtins and coworkers, and by the Rao group (Chidambaram et al., 1999; Vaidhyanathan et al., 2001), has shown that the assembly of anionic metal oxalate frameworks is highly dependent on the choice of guests. Selection of different, sterically larger cations was found to be critical to the formation of alternative three-dimensional frameworks of $(10,3)$-topology (Pointillart et al., 2004), as opposed to hcb-frameworks analogous to those observed in the two minerals, when smaller counterions were introduced. The use of monovalent instead of divalent counterions also enabled the formation of analogous frameworks based on a combination of divalent and trivalent metal nodes. (Decurtins et al., 1994). This work clearly demonstrated that the positively charged counterions actively participate in templating the topology and determining the composition of the final framework structures. It is, therefore, not unimaginable that the formation of hcbsheets in zhemchuzhnikovite and stepanovite is also dictated by the presence of $\mathrm{Mg}\left(\mathrm{H}_{2} \mathrm{O}\right)_{6}^{2+}$ guests, as well as that further open oxalate framework minerals exist that exhibit either the hcb- or the $(10,3)$ topology structure.

The potential diversity of oxalate mineral MOFs is suggested by the great variety of materials that have already been prepared artificially (Cheetham \& Rao, 2005). Other materials isostructural to stepanovite and zhemchuznikovite have been prepared in which the oxalate ligand was replaced with other chelating groups 
such as bispyrimidines or bisimidazoles. This replacement is possible owing to the very similar bite angle between these ligands and oxalic acid. Replacing a diacid with a charge neutral ligand such as bispyrimidine also allows for utilizing metal centers of differing oxidation states or the inclusion of a charge neutral guest or solvent (Armentano et al., 2003; Munno et al., 1995). Keeping in mind that azolate species have been observed in nature (i.e. in chanabayaite and triazolite), it would not be completely surprising to find an oxalate-azolate mixed mineral isostructural to either stepanovite or zhemchuzhnikovite.

Zhemchuzhnikovite and stepanovite are not isolated cases of open oxalate MOFs in mineralogy: deveroite is a cerium(III)-based mineral with the empirical formula $\mathrm{Ce}_{2}\left(\mathrm{C}_{2} \mathrm{O}_{4}\right)_{3} \cdot 10 \mathrm{H}_{2} \mathrm{O}$, which crystalizes in the $P 2_{1} / c$ space group and displays an open distorted hcb-framework (Ollendorff \& Weigel, 1969). Deveroite is isostructural to open-framework compounds of Nd, Pr, Gd, Ce, Eu, Ho, Tb, Dy, Er and Sm that have been known since the 1970s (Hansson et al., 1973; Chi, 1970; Wang et al., 2013; Liu et al., 2011; Rong-Hua \& Han-Guo, 2007; Ollendorff \& Weigel, 1969; Zhang et al., 2014), and is structurally also very similar to analogous frameworks of $\mathrm{Yb}$, Sc and Lu (Hansson et al., 1973). This is not that surprising given the similarity in size and chemistry between the mentioned lanthanides. In deveroite, and all these isostructural or structurally similar materials, the trivalent lanthanide cation is coordinated with three oxalate anions, which also act as ligands bridging neighboring metal centers to form a charge-neutral honeycomb net. Each metal center is also coordinated with two or three water molecules, depending on the metal (Fig. 8a).

Besides the framework structure seen in deveroite and its synthetic analogs, other topologically distinct lanthanide oxalate MOFs have been obtained synthetically, for example square-grid (sql-topology) layered anionic frameworks that have been reported for several lanthanide ions, in the presence of alkaline metal, ammonium or hydronium ions as chargebalancing cations (Fig. 8b) (Bataille \& Louër, 1999; McDonald \& Spink, 1967; Steinfink \& Brunton, 1970; Chapelet-Arab et al., 2006). While such alternative framework structures could be possible candidates for not yet discovered carbon-based minerals in the context of the CMC, their formation is expected to take place in at least mildly acidic environments. Consequently, the so far exclusive observation of only the hcbstructure in minerals provides a hint of geological conditions under which deveroite and related minerals may have formed.

Not much is known about the physico-chemical properties of zhemchuzhnikovite, stepanovite or deveroite, but analogies with synthetic systems raise the very exciting prospect that such MOF minerals could exhibit highly sophisticated and functional properties, such as excellent proton conductivity, selective adsorption of different small molecules, possibly coupled with luminescence in the case of lanthanide-based MOFs (Zhang, Xie et al., 2017). For example, both the overall structure and the arrangement of hcb-layers in zhemchuzhnikovite are strikingly similar to those seen in analogous zincbased MOFs reported by the Kitagawa group (Sadakiyo et al.,
2014). Such metal oxalate MOFs exhibit high proton conductivity due to Grotthuss-type proton hopping processes (Miyatsu et al., 2014) involving water molecules from interstitial layers, as well as deliberately introduced protic guests (e.g. $\mathrm{NH}_{4}{ }^{+}$, adipic acid). The proton conductivity in such MOFs was as high as $8 \mathrm{mS} \mathrm{cm}^{-1}$ and could be readily controlled by hydration/dehydration, resulting in a material that could act as an insulator, a moderate proton conductor, or a superionic conductor, depending on the degree of hydration (Sadakiyo et al., 2014). Moreover, the same group also reported a series of analogous hcb-MOFs exhibiting high selectivity in adsorption of methanol and water, compared to ethanol (Sadakiyo et al., 2016). It remains unclear if zhemchuzhnikovite and other oxalate MOF minerals also exhibit such advanced properties, and how that would influence the geological evolution of Earth or other planetary systems.

\section{Triazolate-based minerals and frameworks}

Triazole is one of a family of azoles (Fig. 9), cyclic 5-membered organic rings containing one (pyrrole), two (imidazole), three

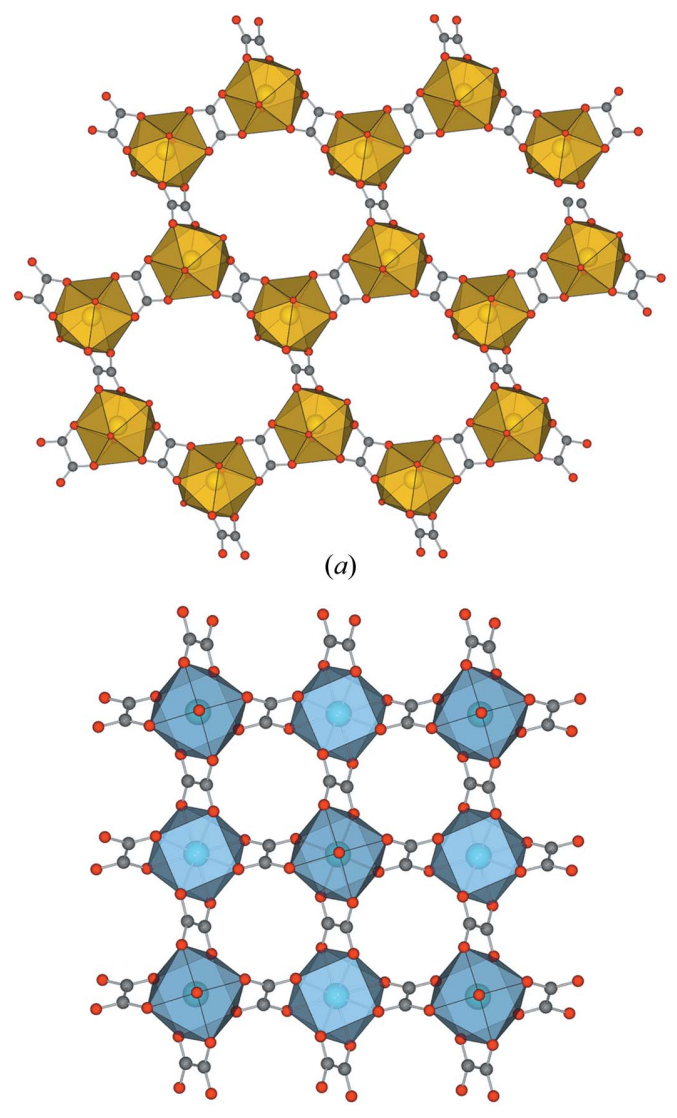

(b)

Figure 8

(a) View of a single layer of hcb-topology in the crystal structure of deveroite $\mathrm{Ce}_{2}\left(\mathrm{C}_{2} \mathrm{O}_{4}\right)_{3} \cdot 10 \mathrm{H}_{2} \mathrm{O}$, water guests in the pores have been omitted for clarity (Ollendorff \& Weigel, 1969) and (b) sql-topology in the crystal structure of hydronium erbium(III) oxalate hydrate, $\left(\mathrm{H}_{3} \mathrm{O}\right)_{2} \mathrm{Er}_{2}\left(\mathrm{C}_{2} \mathrm{O}_{4}\right)_{4} \cdot \mathrm{H}_{2} \mathrm{O}$ (CSD reference: ERHOXL; Steinfink \& Brunton, 1970). 
(1,2,3- or 1,2,4-triazole), four (tetrazole) or five (pentazole) nitrogen atoms (Morton, 1946). Azoles have been known in the context of organic chemistry for almost two centuries, they are abundant in biological systems (for example, the amino acids histidine and tryptophan are azole derivatives), and their resonance-stabilized anions (azolates) are well known as excellent ligands in the synthesis of coordination compounds and frameworks (Zhang et al., 2012).

Despite the abundance of azoles and their derivatives in chemistry, materials science and biology, the first and so far only, examples of azole-based minerals were reported only recently. Specifically, chanabayaite (Chukanov et al., 2015) and triazolite (Chukanov et al., 2018) are a pair of 1,2,4-triazolatebased minerals that were discovered in Pabellón de Pica, Chile in 2015 and 2016, respectively. Both mineral species were discovered in a cormorant guano deposit atop chalcopyrite bearing gabbro, and are associated with salamoniac, halite, dittmarite, joanneumite, nitratine, natroxalate and möhnite minerals. The minerals are described as blue prismatic crystals occurring in radial aggregates up to $1.5 \mathrm{~mm}$ across, with a Mohs hardness of 2 (Fig. 10a). Elemental analysis has revealed

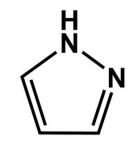

pyrazole

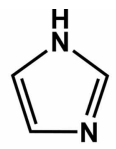

imidazole

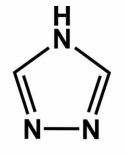

1,2,4-triazole

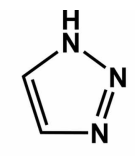

1,2,3-triazole

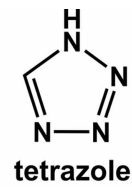

Figure 9

Molecular structures of different azoles.

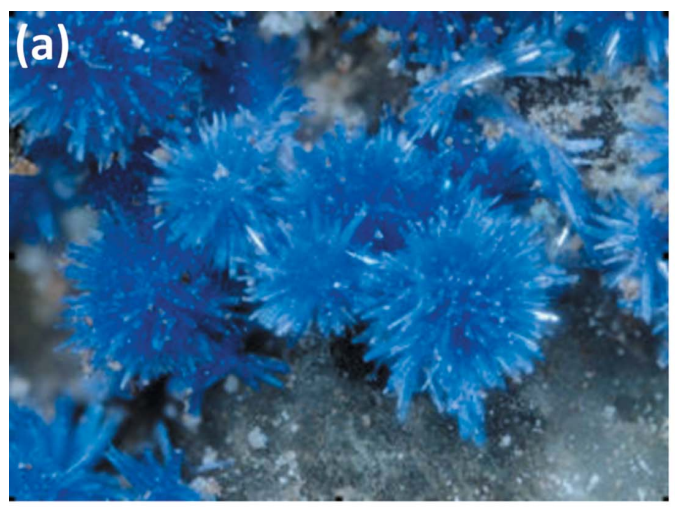

(b)
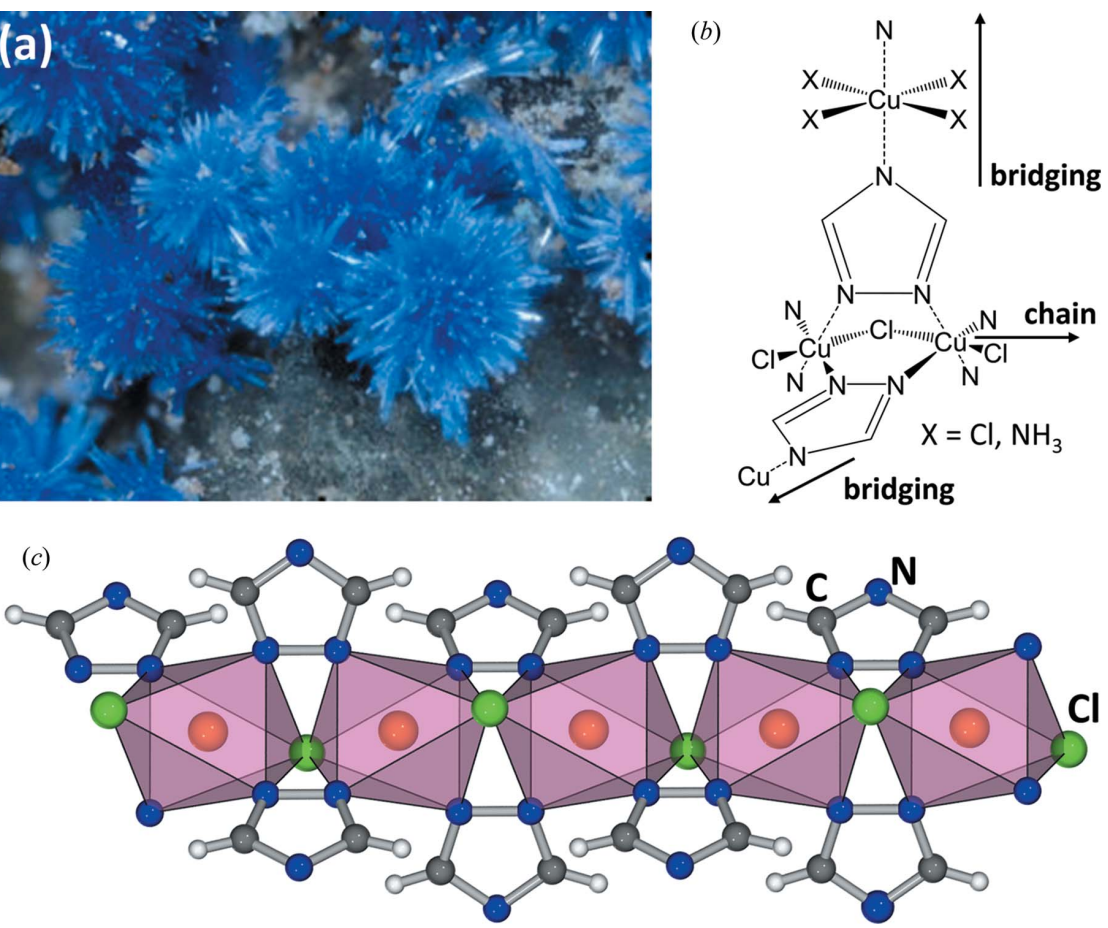

Figure 10

(a) A cluster of triazolite crystals (photo courtesy of Dr Marko Burkhardt). (b) Coordination environment around a triazolate ligand in both triazolite and chanabayaite. (c) Fragment of the one-dimensional SBU in structures of triazolite, chanabayaite, as well as btzb- and btzeMOFs, with octahedra representing the coordination environment of copper ions in the SBU.

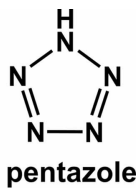

pentazole that, besides nitrogen and carbon, the minerals also contain copper, chlorine, water and ammonia. In addition to this, the structure of the mineral triazolite contains sodium and chlorine. The collected crystalline specimens were of sufficiently high quality to allow for structure solution using singlecrystal X-ray diffraction, revealing in both cases metalorganic three-dimensional framework structures, containing copper(II) ions coordinated with 1,2,4-triazolate anions (Fig. 10b). The framework can be described as consisting of secondary building units (SBUs) that are linear chains of copper(II) ions bridged by chloride anions and nitrogen atoms in the 1,2-positions of each azolate ion (Fig. 10c). Such linearchain SBUs (Schoedel et al., 2016) composed of triazolatemetal ions, with or without additional bridging alogen atoms, are a robust structural motif that has previously been observed in a large number of structures containing iron, nickel, cobalt cadmium, zinc, vanadium, (Habib et al., 2009; Sharga et al., 2010, Lysenko et al., 2010; Liang et al., 2010; Savard et al., 2011; Cui et al., 2012). In chanabayaite and triazolite, these chainlike SBUs are further crosslinked into a three-dimensional open framework structure through additional copper(II) ions that are coordinated with additional ammonia molecules, and bind to the nitrogen atoms in the 4-position of the azolate ligands coming from different chains.

Whereas the structures of triazolite and chanabayaite are unique in the context of mineralogy, they are the direct analogs of the microporous MOFs developed by Janiak, Domasevitsch and other groups. Specifically, by using the organic molecule 1,4-bis(1,2,4triazol-4-yl)benzene (btzb) as a rigid ditopic linker to form complexes with copper(II) halides, Wang et al. have obtained a MOF isostructural to chanabayaite (Figs. 11a and $11 b)$, adopting the same space group and very similar unit-cell parameters (Table 2) (Wang et al., 2017).

Consequently, chanabayaite discovered in 2015 represents a direct analog of the btzbMOF that was independently reported in 2017 and was found to exhibit good selectivity for adsorption of ethylene gas over methane at ambient temperature and pressure. The comparison of the crystal structures of the two materials reveals that the copper(II) ions bridging the SBU chains in the structures of chanabayaite and triazolite are effectively playing the role of rigid 1,4phenylene moieties in the synthetic MOF. Consequently, the two minerals can be considered inverted metal-organic frameworks (IMOFs) of the synthetic MOF design (Papaefstathiou \& MacGillivray, 2002). Importantly, the topologically identical 
structural blueprint has previously been accomplished in MOFs with other bridging organic ligands, such as the one formed with the less rigid trans-bis(1,2,4-triazol-4-yl)ethene (btze) (Fig. 11c), and which also exhibits crystallographic parameters similar to those of chanabayaite. Another way of comparing the structures of the minerals to those of btzb- and btze-based MOFs is through the angle $\varphi$ (Fig. 11b) formed by the linkers that bridge the neighboring SBU chains: $73^{\circ}$ for the btzb-MOF, $\sim 67^{\circ}$ for both minerals and $54^{\circ}$ for the btze-MOF. The topological and crystallographic similarity of chanabayaite and triazolite to MOFs based on either rigid or flexible

(a)

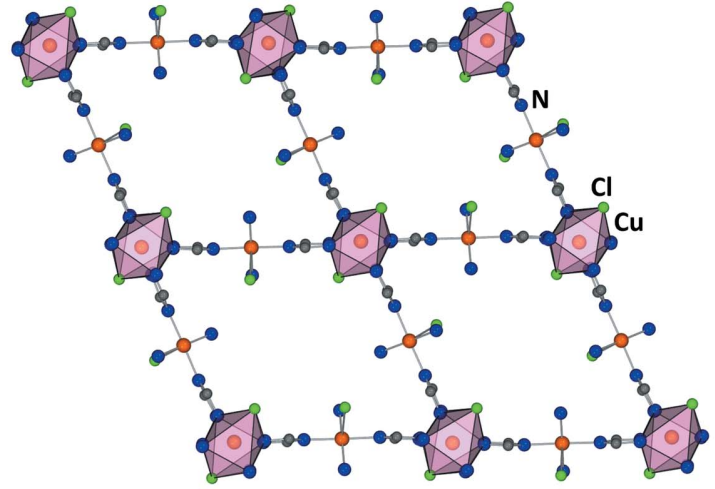

(b)

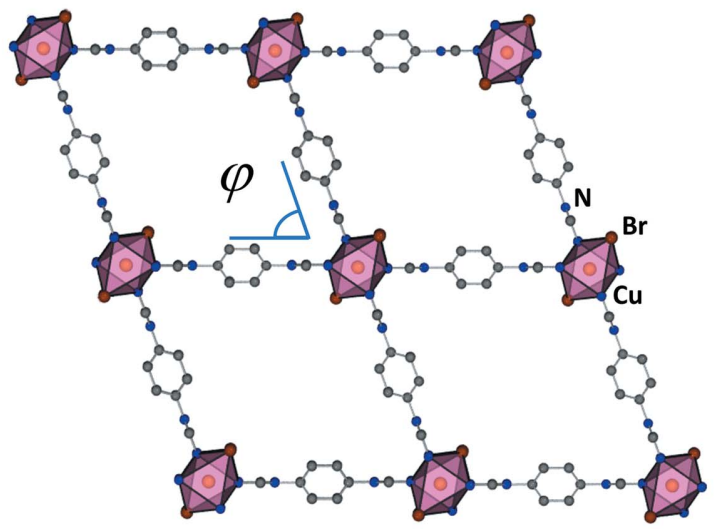

(c)

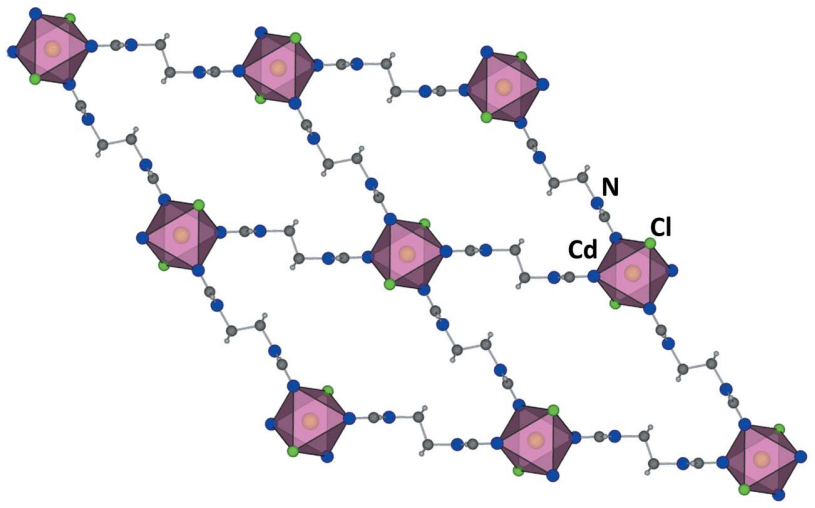

Figure 11

Fragment of the crystal structure of $(a)$ triazolite, viewed along the crystallographic $b$ direction; (b) the copper-containing btzb-MOF, viewed along the crystallographic $b$ direction, highlighting the angle $\varphi$, (CSD reference: XANMUX; Wang et al., 2017); and (c) the cadmium-containing btze-MOF, viewed along the crystallographic $a$ direction. All framework guests have been omitted for clarity (CSD reference: TIDLID; Cui et al., 2012).
Table 2

Crystallographic parameters of chanabayaite, triazolite, btzb-MOF (CSD reference: XANMUX) and btze-MOF (CSD reference: TIDLID).

\begin{tabular}{lllll}
\hline Structure & Triazolite $\dagger$ & Chanabayaite $\ddagger$ & btzb-MOF $\S$ & btze-MOF \\
\hline Space group & $P 2_{1} 2_{1} 2_{1}$ & Imma & Imma & Imma \\
$a(\AA)$ & $19.3575(5)$ & $19.484(3)$ & $21.526(3)$ & $7.620(2)$ \\
$b(\AA)$ & $7.1572(2)$ & $7.2136(10)$ & $7.3473(9)$ & $20.963(6)$ \\
$c(\AA)$ & $12.5020(4)$ & $11.999(4)$ & $14.680(2)$ & $9.876(3)$ \\
\hline
\end{tabular}

$\dagger$ Chukanov et al. (2018). † Chukanov et al. (2015). § Wang et al. (2017). @ Cui et al. (2012).

1,2,4-triazole derivatives is indicative of the high robustness of this type of MOF structure and the underlying SBU. Indeed, a similar open structure is obtained with the btzb ligand even if the neighboring SBUs are not directly linked, as shown by the Domasevitsch group (Bondar et al., 2008), who reported a material consisting of identical chloride- and 1,2,4-triazolatebased chain SBUs, and in which the open-channel structure is sustained by $\pi-\pi$ stacking of btzb units radiating from neighboring SBUs.

Compared to chanabayaite, which is based on an open neutral three-dimensional framework, the structure of triazolite is based on a negatively charged network due to additional chloride anions associated with copper(II) ions bridging the neighboring SBUs. The negative charge is compensated for by hydrated sodium ions found in the square channels of the mineral MOF. It was proposed that triazolite might be the precursor phase of chanabayaite, with the latter forming through partial dehydration and leaching of sodium chloride from triazolite. Whereas the reported chemical formula for chanabayaite accounts for only about $60 \%$ of occupied unitcell volume, it remains unclear whether the mineral exhibits intrinsic porosity or whether there are unresolved, probably disordered, water, ammonia or other species included within the cavities of the natural metal-organic framework. The exact biogeological origin of 1,2,4-triazole in nature is so far unknown. However, we note that the Chen group (Zhang et al., 2005) have shown that triazoles can form in situ from mixtures containing nitriles, ammonia and $\mathrm{Cu}^{\mathrm{II}}$ ions under solvothermal conditions, offering a potential route for the formation of 1,2,4-triazole units in a geological environment. Importantly, it was also shown the reaction might be highly dependent on the presence of $\mathrm{Cu}^{\mathrm{II}}$ ions, as no azolate ring formation was observed in the presence of $\mathrm{Ni}^{\mathrm{II}}$. This suggests a potential explanation why triazolate-based minerals have not yet been observed with other metal ions.

The 1,2,4-triazolate and its derivatives enable the synthesis of a rich variety of coordination complexes and frameworks, some of which were summarized in an excellent review (Haasnoot, 2000). This suggests that a range of other potential MOF minerals could be discovered, based on the 1,2,4-triazolate ions. Indeed, even when considering only the components found in chanabayaite, a wide range of other crystalline phases are possible. This was demonstrated in 2006 by the $\mathrm{Lu}$ group (Zhai et al., 2006) who obtained at least three different phases composed of copper ions, 1,2,4-triazolate ligands and 


\section{mineralogical crystallography}

chloride anions, by performing a solvothermal synthesis in the presence of different concentrations of chloride. More recently, the Walton group (Huang et al., 2011) reported a homochiral srs-topology three-dimensional framework that is compositionally similar to chanabayaite, but based on $\mathrm{Cu}^{\mathrm{I}}$ metal ions in combination with 1,2,4-triazolate and chloride anions. This framework was found to undergo single-crystal-to-single-crystal oxidative transition of $\mathrm{Cu}^{\mathrm{I}}$ to $\mathrm{Cu}^{\mathrm{II}}$ with retention of topology, yielding a material that features the same chemical species as triazolite, but in a different stoichiometric ratio. While these MOF studies found in recent chemistry literature point to the existence of other 1,2,4-triazolate-containing minerals, they also indicate that such naturally found structures could exhibit interesting and advanced functional properties. All azolate ions except pyrrolate, which is monodentate and therefore of not much value in the context of framework synthesis, and pentazolate, which was only recently isolated and structurally characterized (Arhangelskis et al., 2018; Zhang, Sun et al., 2017; Xu et al., 2017), exhibit high stability and have been utilized in the synthesis of open MOF materials. Following the recent discovery of chanabayaite and triazolite, it does not seem impossible that other types of azolate MOFs will be identified as naturally occurring minerals. Indeed, even the appearance of pentazolate structures would not be unexpected under harsh geological environments, i.e. under meteoric impact or under high pressures in the Earth's mantle, as metal pentazolates have been observed to form from elementary metals in the presence of molecular nitrogen $\mathrm{N}_{2}$ under high pressures (Steele et al., 2017; Laniel et al., 2018). However, we believe that the most likely candidates for new azolate-based minerals might be zeolitic imidazolate frameworks (ZIFs) based on tetrahedral metal ions (e.g. $\mathrm{Zn}^{2+}$, $\mathrm{Co}^{2+}$ ) and bridging imidazolate ligands (Zhang et al., 2012; Park et al., 2006). Notably, whereas the imidazole fragment is found in the aminoacid histidine, ZIFs were found to readily form upon reaction of mineral-like precursors, metal oxides or carbonates, with imidazole ligands under mild conditions, yielding topologically different (Katsenis et al., 2015; Akimbekov et al., 2017) open or close-packed framework structures depending on the environment.

\section{Supramolecular synthons in minerals: cyanuric and uric acid minerals}

The formation of hydrogen-bonded synthons is a central feature of crystal engineering and requires the participation of molecular species bearing functional groups that have a rigid structure and can engage in specific molecular recognition motifs. These requirements are found in a recently identified mineral joanneumite, discovered at the same time, and in the same locality as chanabayaite (Bojar et al., 2017). The mineral forms violet microcrystalline aggregates or, in some instances, presents well-shaped cubes. The cube-shaped crystals are most probably pseudomorphs after a not yet identified mineral. Joanneumite is so far the only mineral recognized to contain cyanuric acid, which is an important industrial compound of composition $\mathrm{C}_{3} \mathrm{H}_{3} \mathrm{~N}_{3} \mathrm{O}_{3}$ that appears in keto or enol forms. Due to the poor quality of mineral samples, the crystal structure of joanneumite was determined using synthetically obtained single crystals, which revealed that the mineral is a square-coordinated complex of copper(II) with singly deprotonated cyanurate and ammonia ligands. The cyanurate anions engage in the formation of $R_{2}^{2}(8)$ hydrogen-bonded rings involving two $\mathrm{N}-\mathrm{H}$.. O hydrogen bonds, resulting in the formation of hydrogen-bonded ribbons that are bridged by copper(II) ions to form sheets, comprised of 4-membered hydrogen-bonded rings (Fig. 12). Whereas the composition and structure of joanneumite are novel, and certainly unusual in the context of mineral science, they are very established in coordination chemistry and crystal engineering. The synthetic analog of joanneumite has been known since the 1970s (Slade et al., 1973), and the cyanurate ribbon motif is found in many solid-state structures based on cyanuric acid (El-Gamel et al., 2008; Lam et al., 2016). The motif was noted to be robust in the presence of other hydrogen bond acceptor or donor molecules in the crystal structure (Pedireddi \& Belhekar, 2002). The robustness of the cyanurate ribbon motif in the self-assembly of metal cyanurate complexes analogous to joanneumite was explored by Falvello and co-workers, who prepared and structurally characterized nine cyanurate-containing complexes, including one isostructural to joanneumite (Falvello et al., 1999). The cyanurate ribbon motif was observed in all cases, even in presence of bulky ligands (e.g. triphenylphosphine) introduced onto the metal center in order to create a sterical impediment for the formation of the motif (Falvello et al., 1997, 1995). The origin of cyanurate ligands in joanneumite is not fully understood. A possible origin of the cyanuric acid in nature could be through thermal decomposition of uric acid in the presence of urea or similar compounds, a reaction first described by Wöhler (1828), or possibly as a product in the reaction of metal salts or oxides with urea, as described by Taylor (1972). 
The formation of robust hydrogenbonded synthons is also seen in the minerals uricite and tinnunculite, that are both naturally occurring forms of uric acid. Uric acid is a biogenic, naturally abundant molecule produced by the metabolic degradation of purinebased nucleotides and is commonly found in urine. It is also a critical component of gout, a painful medical condition that results from the accumulation of crystals of uric acid and its salts in the synovial fluid of the joints. Consequently, crystal growth and different crystalline forms of uric acid have attracted a significant amount of research (Sours et al., 2002; Sattar et al., 2008; Zellelow et al., 2010). Uricite represents a mineral form of anhydrous uric acid (AUA) and occurs as soft, yellowish needles, discovered in bird (owls or kestrels) guano deposits in Dingo Donga Cave in Eucla, Western Australia (Bridge, 1974). Tinnunculite, on the other hand, is the mineral form of uric acid dihydrate (UAD), named after the common kestrel (falco tinnunculus), and was discovered recently at Rasvumchorr Mt, Murmanskaya Oblast', Russia (Pekov et al., 2016). The mineral tinnunculite should not be confused with a proposed mineral species of the same name, which was discovered at a burning coal dump in Chelyabinsk, Russia, but was rejected by the IMA on account of its anthropogenic nature (Chesnokov \& Shcherbakova, 1991). Both minerals are isostructural to the previously published structures of synthetic samples: the crystal structure of uric acid dihydrate was explored by Ringertz (1965) and by Artioli and co-workers (Artioli et al., 1997). This orthorhombic structure was revisited by Parkin and Hope (1998), who established it was monoclinic. Structural analysis of anhydrous uric acid was reported by Ringertz (1966).

Both uricite and tinnunculite should best be described as being based on hydrogen-bonded tapes of uric acid molecules that assemble through the formation of $R_{2}^{2}(8)$ homosynthons involving either pairs of 2-imidazolone or pairs of imide moities of uric acid molecules (Fig. 13). In uric acid, the nearest-neighbor tapes adopt an almost perpendicular orientation and are connected by $\mathrm{N}-\mathrm{H} \cdots \mathrm{O}$ interactions into a dense three-dimensional hydrogen-bonded structure. The crystal structure of uric acid dihydrate is strikingly similar to the anhydrous compound, but now the nearest-neighbor tapes are not directly hydrogen bonded, but are bridged by water molecules acting as donors and acceptors of hydrogen bonds. This results in the formation of additional hydrogen-bonded rings on each uric acid molecular ribbon of $R_{3}^{2}(9)$ and $R_{3}^{2}(8)$ structure. As the dimensions and structure of uric acid ribbon motifs remain virtually unchanged between the two crystal structures, the unit-cell dimensions of the two forms of mineral uric acid are very close with the ribbons extending in the (210) and (210) directions in the dihydrate and the directions (021) and (02) in the anhydrous structure. This is consistent with

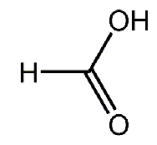

formic acid

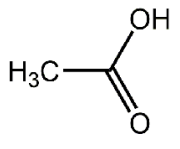

acetic acid<smiles>O=C(O)c1c(C(=O)O)c(C(=O)O)c(C(=O)O)c(C(=O)O)c1C(=O)O</smiles>

mellitic acid

Figure 14

Schematic representation of formic, acetic and mellitic acids.

the observation that the anhydrous form of uric acid forms epitaxially on crystals of the dihydrate, with contact between the two phases being formed between the (010) planes of the previously considered orthorhombic structure of the dihydrate and the (100) planes of the anhydrous compound (Artioli et al., 1997). Interestingly, synthetic crystals of uric acid dihydrate undergo a rapid, irreversible dehydration at $298 \mathrm{~K}$ in air (Zellelow et al., 2010), or somewhat slower in aqueous solutions, but the natural occurring forms were observed to be more stable under the same conditions. (Ringertz, 1965; Artioli et al., 1997).

\section{Other metal carboxylate minerals}

Besides oxalic acid, compounds of other organic carboxylic acids can be found as organic minerals. Among these, the most prominent examples are metal derivatives of formic, acetic and mellitic acids (Fig. 14). There are a vast number of biological sources of formate and acetate species found in such minerals, as the corresponding acids appear in many plant, animal and bacterial metabolic processes (Vranova et al., 2013). On the other hand, the origin of mellitic acid in geological environments is not completely understood, but it was recently proposed that mellitic acid can form by oxidative degradation of graphite in coal (Plater \& Harrison, 2015). Indeed, it is noted that the mineral mellite, a hydrated aluminium salt of mellitic acid, is often found in association with lignite coal deposits (Robl \& Kuhs, 1991). It was also noted that mellitic acid, as well as similar non-volatile, 
aromatic compounds, could form in a harsh and oxidative environmental conditions, under continuous high-energy irradiation, such as are those present on the surface of Mars (Benner et al., 2000; Blanco et al., 2013).

\subsection{Metal formate frameworks as minerals}

To date, only two organic minerals based on formic acid have been reported, namely formicaite and dashkovaite (Chukanov et al., 1999, 2000), discovered in the EasternSiberian region in Russia. Although often characterized as salts, the two minerals represent formate-based coordination polymers of calcium and magnesium, respectively. Both minerals appear as white solids, with a dense, close-packed structure, and are also quite soft, with a Mohs hardness of 1 . Formicaite was named after its constituent formic acid, and dashkovaite after Yekaterina R. Vorontsova-Dashkova, the president of the Russian Academy of Sciences (1782-1796). The structure of formicaite comprises calcium cations in a slightly distorted octahedral environment, coordinated by six formate anions with $\mathrm{Ca}-\mathrm{O}$ separations between $2.31 \AA$ and $2.48 \AA$. Each formate ion bridges three $\mathrm{Ca}^{2+}$ cations, with one of the carboxylate oxygen atoms acting as a single donor atom, and the other adopting a $\mu_{2}$ bridging geometry. This arrangement produces a non-porous three-dimensional coordination network that crystallizes in the space group $P 4_{1} 2_{1} 2$, representing an example of non-chiral components crystal-

(a)

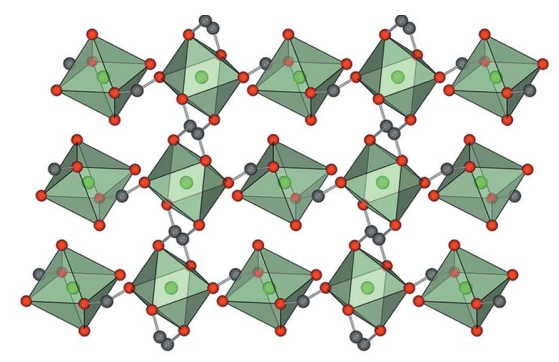

(b)

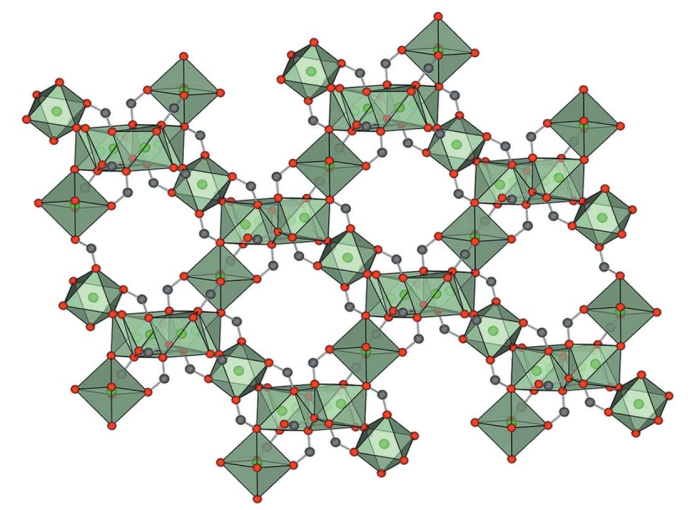

lizing in a non-centrosymmetric arrangement (Matsui et al., 1980). Importantly, whereas formicaite is the only currently known mineral form of calcium formate, the synthetically prepared material can also appear in an alternative polymorphic form, adopting a centrosymmetric structure and crystallizing in the space group Pbca (Burger et al., 1977). This polymorph has not yet been observed in nature; however, it could very possibly exist in a natural environment.

The mineral dashkaovite is a dihydrate of magnesium formate, and its structure consists of two different types of magnesium cations, both octahedrally coordinated by oxygen atom ligands. In one type, the $\mathrm{Mg}^{2+}$ ions are surrounded by oxygen atoms of formate ions only, while in the other type each $\mathrm{Mg}^{2+}$ is coordinated by four water molecules in equatorial positions, as well as two axially coordinated formate anions. The magnesium cations in the structure are bridged by formate anions, producing a distorted two-dimensional square-grid (sql-topology) metal-organic framework. Whereas the structure of dashkovaite is close-packed, it is important to note that magnesium formate porous frameworks have been prepared in the laboratory and can be evacuated under reduced pressure and/or elevated temperatures (maximum $240^{\circ} \mathrm{C}$ ) to yield microporous $\mathrm{MOFs}$ with surface areas between 150 and $500 \mathrm{~m}^{2} \mathrm{~g}^{-1}$ (Rood et al., 2006; Dybtsev et al., 2004; Spanopoulos et al., 2015). This particular type of magnesium formate MOF has also been commercialized by BASF under the name Basosiv M050 and is also

(c)

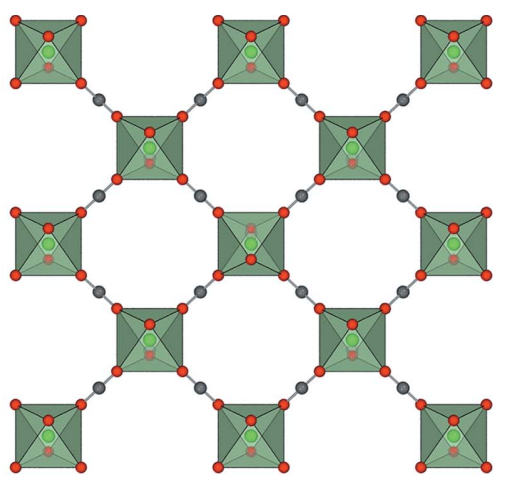

(d)

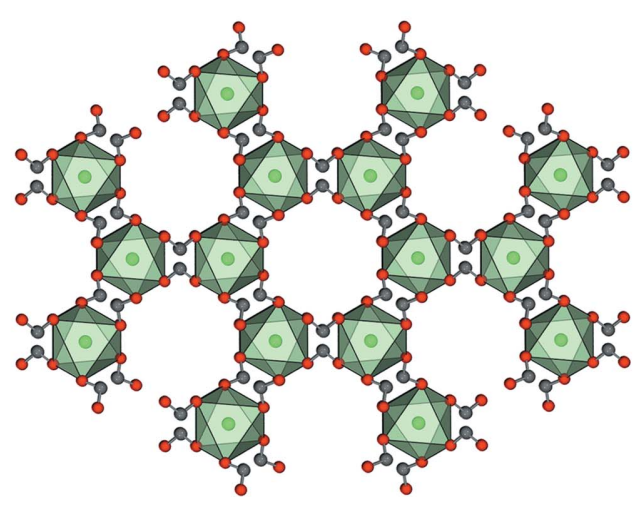

Figure 15

Crystal structures of different magnesium formate frameworks, with green octahedra representing the coordination environments of $\mathrm{Mg}^{2+}$ ions: $(a)$ dashkovaite (CSD reference: MGFORD04; Rossin et al., 2008); (b) magnesium formate MOF with the crs-topology, known as Basosiv M050 (CSD reference NAXVOY01; Rood et al., 2006); (c) anionic magnesium formate framework of pcu-topology (CSD reference: SIRBIG07; Shang et al., 2014) with ethylammonium guests omitted for clarity; and $(d)$ anionic magnesium formate framework of acs-topology (CSD reference: NIWPIU; Mączka et al., 2014) with ammonium guests omitted for clarity. 
offered by specialty manufacturers. Other magnesium formate open frameworks have also been synthesized, for example, the anionic open structures obtained in the presence of selected ammonium cations (Figs. 15c and 15d) (Maczka et al., 2014; Shang et al., 2014; Rossin et al., 2008). Notably, formate frameworks have been also been of interest because of their magnetic properties, as in the case of gadolinium formate (Lorusso et al., 2013) used as a magnetic refrigerant.

Such demonstrated structural diversity and structural robustness invite speculation that other types of magnesium formate frameworks could also be found in minerals, potentially in the presence of suitable structure-templating species. A potential route to such materials could be the reported 'aging' or milling reactions, wherein the exposure of a metal oxide or a carbonate to small organic molecules leads to the assembly of more complex coordination polymers or MOFs. Our group, and others, have previously shown that exposure of $\mathrm{MgO}$ to a variety of organic carboxylic acid molecules produces salts, coordination complexes or polymers of different complexity, depending on reaction conditions (Chow et al., 2010; Friščić et al., 2011; Chen et al., 2010).

6.2. Metal acetate minerals: complex SBUs and mixed-metal coordination polymers

Acetate appears as the ligand and anion in several organic minerals, of which we will focus on two copper-based species, hoganite and paceite. Hoganite is a mineral form of copper(II) acetate monohydrate, and occurs as blue monoclinic crystals, with a Mohs hardness of 1.5 . While hoganite was originally discovered along with paceite in the Potosi mine in New South Wales, Australia (Hibbs et al., 2002), it has since also been found in Morocco and Arizona, USA. These two acetate minerals are generally associated with goethite, hematite, quartz, cerussite as well as other copper-containing mineral species such as linarite, malachite, azurite and cuprian smithsonite. It is worth noting that despite the ubiquitous occurrence of acetic acid in nature, acetate minerals are quite rare, which might be explained by the high aqueous solubility of most metal acetates. Such an explanation is consistent with the observation that hoganite has been found in the dry, hot climates of Morocco, Arizona and Australia. The crystal structure of hoganite is particularly interesting, as it is so far the only mineral occurrence of the 'paddlewheel' unit that is well known in coordination chemistry and MOF design involving copper, zinc, cobalt and other transition metals. The paddlewheel unit in hoganite consists of an isolated binuclear complex of two copper(II) ions that are bridged by four acetate units and capped by a coordinated water molecule at each end (Fig. 16a). The copper atoms in the paddlewheel are quite close, the distance between them being $\sim 2.61 \AA$ which is slightly longer than the $\sim 2.56 \AA$ distance in metallic copper.

The paddlewheel SBU has famously been utilized in a number of MOFs, notably the HKUST-1 (acronym of Hong Kong University of Science and Technology) material, which is an extended open framework with trimesic acid anions as bridging carboxylate ligands (Chui et al., 1999). The HKUST-1 is one of the most extensively studied, widely used as well as commercialized MOFs, exhibiting square channels approximately $10 \AA$ in diameter and a thermal stability of up to $240^{\circ} \mathrm{C}$. The CSD contains over 1500 entries involving the paddlewheel unit based on $\mathrm{Cu}^{\mathrm{II}}$ alone, which attests to the stability and reliability of this self-assembled motif. The appearance of this SBU in a geological environment is consistent with its robustness and hints at the possibility of broader occurrence of paddlewheel-based MOFs as mineral species. Preformed acetate SBUs and acetate clusters have been used extensively in the chemistry of coordination polymers as convenient starting materials (Fidelli et al., 2018; Užarević et al., 2016; Bezrukov et al., 2018).

Paceite, observed as dark blue prismatic crystals growing on hoganite specimens, exhibits a very different structure to hoganite. The structure of paceite consists of one-dimensional polymer chains, in which the square planar coordinated copper(II) cations are connected to calcium ions, themselves octahedrally coordinated by acetate ions and water. In such infinite $\mathrm{Cu}-\mathrm{Ca}-\mathrm{Cu}-\mathrm{Ca}$ one-dimensional chain assembly, two acetate units bridge each $\mathrm{Cu}^{2+}$ with each of the two neighboring $\mathrm{Ca}^{2+}$ ions (Fig. 16b). Although simple, the paceite structure is of considerable importance in the context of designing complex metal-organic materials. Namely, the ability to arrange multiple, chemically distinct metal centers has been the topic of a number of recent studies, directed towards creating increasingly complex solid-state environ- (a)

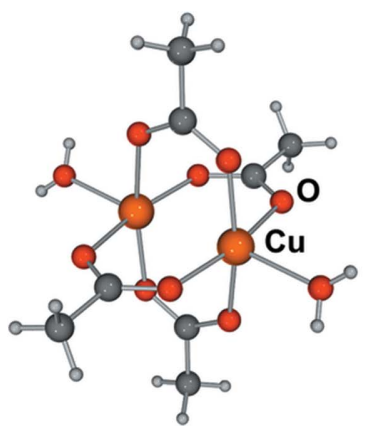

(b)

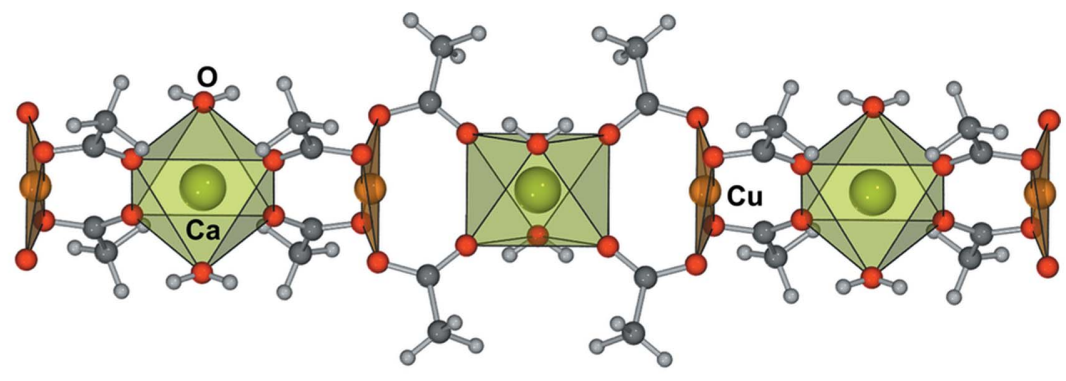

Figure 16

(a) Single 'paddlewheel' binuclear cluster in the structure of copper(II) acetate hydrate (hoganite) and (CSD reference: CUAQAC; van Niekerk \& Schoening, 1953) and $(b)$ fragment of a coordination polymer chain in paceite, composed of square-planar coordinated $\mathrm{Cu}^{2+}($ orange plane) and octahedrally coordinated $\mathrm{Mg}^{2+}$ (green octahedra) cations, bridged by pairs of acetate ligands (CSD reference: CACUAC; Klop et al., 1983). 
ments in MOFs that could be used, for example, to conduct complex, multi-step chemical transformations within the confined nanospaces of the framework (Castillo-Blas et al., 2017). Although paceite is not a three-dimensional framework material, it nevertheless points to an interesting design that allows precise positioning of strong $\left(\mathrm{Cu}^{2+}\right)$ and weak $\left(\mathrm{Ca}^{2+}\right)$ Lewis acid cations along a coordination polymer chain.

\subsection{Mellite and mellitic acid}

Mellitic acid is the most complex carboxylic acid found in a mineral composition. It is found in the fully deprotonated anionic form, paired with fully hydrated $\mathrm{Al}\left(\mathrm{H}_{2} \mathrm{O}\right)_{6}{ }^{3+}$ cations, in the mineral mellite (Giacovazzo et al., 1973). As the aluminium cations in mellite are coordinated solely by water molecules, rather than any of the carboxylate groups of the mellitate ion, mellite is a bona fide salt. However, a series of chemically very similar MOFs with trivalent cations $\left(\mathrm{Al}^{3+}\right.$, $\mathrm{Ga}^{3+}$ or $\mathrm{In}^{3+}$ ) have been prepared, allowing for the plausibility of such materials being discovered in nature (Volkringer et al., 2013). The mineral itself was discovered in 1789 in Artern (present day Germany) by the German naturalist C. A. S. Hoffmann (Werner \& Hoffmann, 1789), and has since also been found in Hungary, Russia, Austria and the Czech Republic. It is often found associated with lignite and it is most probably formed from decomposing organic matter. The mineral was named mellite in allusion to its golden yellow color, meli meaning honey in Greek, but also appears in red, brown or gray varieties. The color comes exclusively from the impurities in the material as the synthetically prepared material is white. Mellite has a Mohs hardness of 2.5 and can be polished and cut to make vibrant gemstones. As it contains conjugated organic rings in its structure, mellite fluoresces pale yellow or blue under 254 or $365 \mathrm{~nm}$ ultraviolet light, respectively.

In 2014, Clegg and Holcroft investigated the potential of first row transitional metal mellitates for the design of coordination polymers, including microporous structures (Clegg \& Holcroft, 2014). The comparison of the structures and synthesis conditions for a hundred previously reported (found in the CSD, version 5.35 with updates to February 2014) mellitates of cobalt, nickel and copper, as well as eight new compounds, led to several general conclusions concerning the synthesis of mellitate frameworks:

(i) Hydrothermal synthesis is more likely to result in a product with a lower water content and a denser structure.

(ii) $\mathrm{Co}^{2+}$ and $\mathrm{Ni}^{2+}$ cations in compounds with mellitic acid anions prefer octahedral coordination environments, while $\mathrm{Cu}^{2+}$ prefers a square pyramidal environment.

(iii) Hydroxide ions in structures of metal mellitates are more likely to appear as bridging ligands, and water molecules as terminal capping ligands.

(iv) $\pi-\pi$ stacking of mellitate rings is not possible due to steric hindrance from the carboxylic groups.

While this study also concluded that '.. . [mellitic acid] does not lend itself well to a design approach in its coordination chemistry, in which serendipity plays a significant role', which somewhat limits the attractiveness of mellitic acid for crystal engineering, mellitate coordination polymers with rare earth elements have shown promise in developing fluorescent lightemitting materials (Han et al., 2012). The combination of mellitate anions with different lanthanide metal cations provided several isostructural fluorescent emitters of different colors (red, green and blue). Epitaxially growing the isostructural polymers on each other to form core-shell-shell crystallites, white light emitting systems were created (Luz et al., 2014). Notably, the Rodrigues group has employed such isostructural mellitate coordination polymers in printing invisible, fluorescent markings on paper or plastic foil using a modified commercial inkjet printer (Luz et al., 2015).

\section{Conclusions}

The recent interest in carbon-containing minerals and the need for better understanding of the geological fate of carbon materials has highlighted organic minerals as a small, but rapidly growing class of minerals that cannot be readily adapted to the existing mineral classifications. In this feature article, we have attempted to demonstrate how these 'nonconventional' minerals can be readily and intuitively described through concepts of crystal engineering and advanced materials design. Structures of recently structurally characterized organic minerals, such as zhemchuzhnikovite, deveroite or chanabayaite are paradigm-changing, as they reveal the natural occurrence of sophisticated nanostructured materials, such as metal-organic frameworks (MOFs), that have so far been considered to be of exclusively artificial origin. Indeed, if the structures and properties of organic minerals such as stepanovite or zhemchuzhnikovite were elucidated when they were first reported, it is probable that MOFs would be considered bioinspired functional materials. We hope that this feature article will provide impetus for mineralogists to further explore the unexpectedly close relationship between crystal engineering and mineralogy. As further organic minerals are discovered, we believe that it will be important that terms such as 'supramolecular synthon', 'coordination polymer' or 'metal-organic framework' become a part of mineralogist's vocabulary. Conversely, we encourage materials chemists to take a closer look at geological environments in search for new, advanced materials designs. This is already happening in mechanochemical synthesis of advanced materials (André et al., 2011), accelerated aging employed for the creation of cocrystals and coordination polymers (Huskić, Christopherson et al., 2016; Qi et al., 2014) and mineral transformation reactions (Reboul et al., 2012). Considering the number of unknown organic minerals predicted to be out there, it is probable that one or more of these minerals will have structures and properties that are unprecedented in current materials chemistry. Till then, all we have to do is look.

\section{Acknowledgements}

The authors thank Dr Natalia Zubkova for sharing chanabayaite crystallographic data, Dr Igor Pekov for the image of 
stepanovite, Dr Travis Olds for sharing ewingite crystallographic data and images, Dr Marko Burkhardt for the image of triazolite and Dr Athanassios D. Katsenis for the help with determining the topologies of some structures.

\section{Funding information}

The following funding is acknowledged: Natural Sciences and Engineering Research Council of Canada (grant Nos. RGPIN2017-06467, SMFSU 507347-17 to Tomislav Friščíc); McGill University (Alex MacInnes Fellowship to Igor Huskić).

\section{References}

Aakeröy, C. B. (1997). Acta Cryst. B53, 569-586.

Aakeröy, C. B., Beatty, A. M. \& Helfrich, B. A. (2001). Angew. Chem. Int. Ed. 40, 3240-3242.

Aakeröy, C. B., Scott, B. M. T. \& Desper, J. (2007). New J. Chem. 31, 2044-2051.

Abrahams, B. F., Hoskins, B. F., Michail, D. M. \& Robson, R. (1994). Nature, 369, 727-729.

Adamo, P. \& Violante, P. (2000). Appl. Clay Sci. 16, 229-256.

Akimbekov, Z., Katsenis, A. D., Nagahushana, G. P., Ayoub, G., Arhangelskis, M., Morris, A. J., Friščić, T. \& Navrotsky, A. (2017). J. Am. Chem. Soc. 23, 7952-7957.

Alkordi, M. H., Liu, Y., Larsen, R. W., Eubank, J. F. \& Eddaoudi, M. (2008). J. Am. Chem. Soc. 130, 12639-12641.

Anderson, K. B., Winans, R. E. \& Botto, R. E. (1992). Org. Geochem. 18, 829-841.

André, V., Hardeman, A., Halasz, I., Stein, R. S., Jackson, G. J., Reid, D. G., Duer, M. J., Curfs, C., Duarte, M. T. \& Friščić, T. (2011). Angew. Chem. Int. Ed. 50, 7858-7861.

Arhangelskis, M., Katsenis, A. D., Morris, A. J. \& Friščić, T. (2018). Chem. Sci. 9, 3367-3375.

Armentano, D., de Munno, G., Lloret, F., Julve, M., Curély, J., Babb, A. M. \& Lu, J. Y. (2003). New J. Chem. 27, 161-165.

Artioli, G., Masciocchi, N. \& Galli, E. (1997). Acta Cryst. B53, 498503.

Ashbrook, S. E. \& Dawson, D. M. (2016). Nuclear Magnetic Resonance, Vol. 45, edited by V. Ramesh, pp. 1-52. Cambridge: RSC.

Atencio, D., Coutinho, J. M. V., Graeser, S., Matioli, P. A. \& Menezes Filho, L. A. D. (2004). Am. Mineral. 89, 1087-1091.

Basso, R., Lucchetti, G., Zefiro, L. \& Palenzona, A. (1997). Neues Jahrb. Miner. 2, 84-96.

Bataille, T. \& Louër, D. (1999). Acta Cryst. C55, 1760-1762.

Batten, S. R., Champness, N. R., Chen, X.-M., Garcia-Martinez, J., Kitagawa, S., Öhrström, L., O'Keeffe, M., Paik Suh, M. \& Reedijk, J. (2013). Pure Appl. Chem. 85, 1715-1724.

Batten, S. R., Champness, N. R., Chen, X. M., Garcia-Martinez, J., Kitagawa, S., Öhrström, L., O'Keeffe, M., Suh, M. P. \& Reedijk, J. (2012). CrystEngComm, 14, 3001-3004.

Benner, S. A., Devine, K. G., Matveeva, L. N. \& Powell, D. H. (2000). Proc. Natl Acad. Sci. 97, 2425-2430.

Bezrukov, A. A., Törnroos, K. W., Le Roux, E. \& Dietzel, P. D. C. (2018). Chem. Commun. 54, 2735-2738.

Bhogala, B. R. \& Nangia, A. (2008). New J. Chem. 32, 800-807.

Blanco, Y., Rivas, L. A., Ruiz-Bermejo, M. \& Parro, V. (2013). Icarus, 224, 326-333.

Bojar, H.-P., Walter, F. \& Baumgartner, J. (2017). Mineral. Mag. 81, 155-166.

Bondar, O. A., Lukashuk, L. V., Lysenko, A. B., Krautscheid, H., Rusanov, E. B., Chernega, A. N. \& Domasevitch, K. V. (2008). CrystEngComm, 10, 1216-1226.

Brammer, L. (2017). Faraday Discuss. 203, 485-507.
Breck, D. W. (1973). Zeolite Molecular Sieves: Structure, Chemistry, and Use. New York: Wiley.

Bridge, P. J. (1974). Mineral. Mag. 39, 889-890.

Bučar, D. K., Henry, R. F., Lou, X., Duerst, R. W., Borchardt, T. B., MacGillivray, L. R. \& Zhang, G. G. Z. (2007). Mol. Pharm. 4, 339346.

Bučar, D. K. \& Macgillivray, L. R. (2007). J. Am. Chem. Soc. 129, 32 33.

Burger, N., Fuess, H. \& Mason, S. A. (1977). Acta Cryst. B33, 1968 1970.

Bushuyev, O. S., Corkery, T. C., Barrett, C. J. \& Friščić, T. (2014). Chem. Sci. 5, 3158-3164.

Caley, E. R. \& Richards, J. F. C. (1956). Theophrastus: On Stones Introduction, Greek Text, English Translation and Commentary. Columbus Ohio: Ohio State University.

Castillo-Blas, C., de la Peña-O'Shea, V. A., Puente-Orench, I., de Paz, J. R., Sáez-Puche, R., Gutiérrez-Puebla, E., Gándara, F. \& Monge, Á. (2017). Sci. $A d v$. 3, e1700773.

Cavallo, G., Metrangolo, P., Milani, R., Pilati, T., Priimagi, A., Resnati, G. \& Terraneo, G. (2016). Chem. Rev. 116, 2478-2601.

Chapelet-Arab, B., Duvieubourg, L., Nowogrocki, G., Abraham, F. \& Grandjean, S. (2006). J. Solid State Chem. 179, 4029-4036.

Cheetham, A. K. \& Rao, C. N. R. (2005). MRS Bull. 30, 93-98.

Chen, J., Blume, H. P. \& Beyer, L. (2000). CATENA, 39, 121-146.

Chen, X., Stowell, J. G., Morris, K. R. \& Byrn, S. R. (2010). J. Pharm. Biomed. Anal. 51, 866-874.

Chesnokov, B. V. \& Shcherbakova, T. P. (1991). The mineralogy of burnt dumps of the Chelyabinsk coal basin, Moscow.

Chi, H. (1970). Bull. Chem. Soc. Jpn, 43, 1703-1707.

Chidambaram, D., Neeraj, S., Natarajan, S. \& Rao, C. N. R. (1999). J. Solid State Chem. 147, 154-169.

Childs, S. L. \& Hardcastle, K. I. (2007). Cryst. Growth Des. 7, 12911304.

Chisholm, J. E., Jones, G. C. \& Purvis, O. W. (1987). Mineral. Mag. 51, 715-718.

Chow, E. H. H., Strobridge, F. C. \& Friščić, T. (2010). Chem. Commun. 46, 6368-6370.

Chui, S. S. Y., Lo, S. M. F., Charmant, J. P. H., Orpen, G. \& Williams, I. D. (1999). Science, 283, 1148-1150.

Chukanov, N. V., Belakovskiy, D. I., Malinko, S. V. \& Organova, N. (2000). Zap. Vseross. Mineral. Oba, 6, 49-53.

Chukanov, N. V., Malinko, S. V., Lisitsyn, A. E., Dubinchuk, V. T., Kuzmina, O. V. \& Zadov, A. E. (1999). Zap. Vseross. Mineral. Oba, 2, 43-47.

Chukanov, N. V., Zubkova, N. V., Möhn, G., Pekov, I. V., Belakovskiy, D. I., Van, K. V., Britvin, S. N. \& Pushcharovsky, D. Y. (2018). Mineral. Mag. 82, 1007-1014.

Chukanov, N. V., Zubkova, N. V., Möhn, G., Pekov, I. V., Pushcharovsky, D. Y. \& Zadov, A. E. (2015). Geol. Ore Depos. 57, 712-720.

Clegg, W. \& Holcroft, J. M. (2014). Cryst. Growth Des. 14, 6282-6293.

Cui, Y., Li, B., He, H., Zhou, W., Chen, B. \& Qian, G. (2016). Acc. Chem. Res. 49, 483-493.

Cui, Y. F., Qian, X., Chen, Q., Li, B. L. \& Li, H. Y. (2012). CrystEngComm, 14, 1201-1204.

Decurtins, S., Schmalle, H. W., Oswald, H. R., Linden, A., Ensling, J., Gütlich, P. \& Hauser, A. (1994). Inorg. Chim. Acta, 216, 65-73.

Delori, A., Friščić, T. \& Jones, W. (2012). CrystEngComm, 14, 2350 2362.

De Munno, G., Ruiz, R., Lloret, F., Faus, J., Sessoli, R. \& Julve, M. (1995). Inorg. Chem. 34, 408-411.

Deng, H., Grunder, S., Cordova, K. E., Valente, C., Furukawa, H., Hmadeh, M., Gándara, F., Whalley, A. C., Liu, Z., Asahina, S., Kazumori, H., O'Keeffe, M., Terasaki, O., Stoddart, J. F. \& Yaghi, O. M. (2012). Science, 336, 1018-1023.

Denny, M. W. \& Gosline, J. M. (1980). J. Exp. Biol. 88, 375-393.

Desiraju, G. R. (2010). J. Chem. Sci. 122, 667-675.

Desiraju, G. R. (2013). J. Am. Chem. Soc. 135, 9952-9967. 
Doonan, C. J., Morris, W., Furukawa, H. \& Yaghi, O. M. (2009). J. Am. Chem. Soc. 131, 9492-9493.

Dubey, R., Mir, N. A. \& Desiraju, G. R. (2016). IUCrJ, 3, 102-107.

Duggirala, N. K., Perry, M. L., Almarsson, Ö. \& Zaworotko, M. J. (2016). Chem. Commun. 52, 640-655.

Dybtsev, D. N., Chun, H. \& Kim, K. (2004). Angew. Chem. Int. Ed. 43, 5033-5036.

Dybtsev, D. N., Chun, H., Yoon, S. H., Kim, D. \& Kim, K. (2004). J. Am. Chem. Soc. 126, 32-33.

Echigo, T. \& Kimata, M. (2008). Phys. Chem. Miner. 35, 467-475.

Echigo, T. \& Kimata, M. (2010). Can. Mineral. 48, 1329-1357.

Eddaoudi, M., Moler, D. B., Li, H., Chen, B., Reineke, T. M., O'Keeffe, M. \& Yaghi, O. M. (2001). Acc. Chem. Res. 34, 319-330.

Ekstrom, A., Fookes, C. J. R., Hambley, T., Loeh, H. J., Miller, S. A. \& Taylor, J. C. (1983). Nature, 306, 173-174.

El-Gamel, N. E. A., Wagler, J. \& Kroke, E. (2008). J. Mol. Struct. 888, 204-213.

Ermer, O. (1988). J. Am. Chem. Soc. 110, 3747-3754.

Etter, M. C. (1990). Acc. Chem. Res. 23, 120-126.

Etter, M. C., MacDonald, J. C. \& Bernstein, J. (1990). Acta Cryst. B46, 256-262.

Falvello, L. R., Hitchman, M. A., Palacio, F., Pascual, I., Schultz, A. J., Stratemeier, H., Tomás, M., Urriolabeitia, E. P. \& Young, D. M. (1999). J. Am. Chem. Soc. 121, 2808-2819.

Falvello, L. R., Pascual, I. \& Tomás, M. (1995). Inorg. Chim. Acta, 229, 135-142.

Falvello, L. R., Pascual, I., Tomás, M. \& Urriolabeitia, E. P. (1997). J. Am. Chem. Soc. 119, 11894-11902.

Farha, O. K., Eryazici, I., Jeong, N. C., Hauser, B. G., Wilmer, C. E., Sarjeant, A. A., Snurr, R. Q., Nguyen, S. T., inh, T., Yazaydın, A., Özgür, \& Hupp, J. T. (2012). J. Am. Chem. Soc. 134, 15016-15021.

Fidelli, A. M., Karadeniz, B., Howarth, A. J., Huskić, I., Germann, L. S., Halasz, I., Etter, M., Moon, S.-Y., Dinnebier, R. E., Stilinović, V., Farha, O. K., Friščić, T. \& Užarević, K. (2018). Chem. Commun. 54, 6999-7002.

Fonseca Guerra, C., Bickelhaupt, F. M., Snijders, J. G. \& Baerends, E. J. (2000). J. Am. Chem. Soc. 122, 4117-4128.

Foxman, B. M., Guarrera, D. J., Taylor, L. D., VanEngen, D. \& Warner, J. C. (1998). Cryst. Eng. 1, 109-118.

Friščić, T., Halasz, I., Strobridge, F. C., Dinnebier, R. E., Stein, R. S., Fábián, L. \& Curfs, C. (2011). CrystEngComm, 13, 3125-3129.

Friščić, T. \& Jones, W. (2007). Faraday Discuss. 136, 167-178.

Friščić, T., Kaitner, B. \& Meštrović, E. (1998). Croat. Chem. Acta, 71, 87-98.

Furukawa, H., Go, Y. B., Ko, N., Park, Y. K., Uribe-Romo, F. J., Kim, J., O'Keeffe, M. \& Yaghi, O. M. (2011). Inorg. Chem. 50, 91479152.

Furukawa, H., Kim, J., Ockwig, N. W., O'Keeffe, M. \& Yaghi, O. M. (2008). J. Am. Chem. Soc. 130, 11650-11661.

Gadd, G. M. (1999). Adv. Microb. Physiol. 41, 47-92.

Gadd, G. M. (2010). Microbiology, 156, 609-643.

Gaines, R. V., Skinner, H. C., Foord, E. E., Mason, B. \& Rosenzweig, A. (1997). J. Am. Chem. Soc. 120, 2693.

Genceli Guner, F. E., Lutz, M., Sakurai, T., Spek, A. L. \& Hondoh, T. (2010). Cryst. Growth Des. 10, 4327-4333.

Genceli Güner, F. E., Sakurai, T. \& Hondoh, T. (2013). Eur. J. Mineral. 25, 78-83.

Giacovazzo, C., Menchetti, S. \& Scordari, F. (1973). Acta Cryst. B29, 26-31.

Goldberg, I. (2000). Acta Cryst. A56, s122-s122.

Goldberg, I. (2005). Chem. Commun. pp. 1243-1254.

Gutov, O. V., Bury, W., Gomez-Gualdron, D. A., Krungleviciute, V., Fairen-Jimenez, D., Mondloch, J. E., Sarjeant, A. A., Al-Juaid, S. S., Snurr, R. Q., Hupp, J. T., Yildirim, T. \& Farha, O. K. (2014). Chem. Eur. J. 20, 12389-12393.

Haasnoot, J. G. (2000). Coord. Chem. Rev. 200-202, 131-185.

Habib, H. A., Hoffmann, A., Höppe, H. A., Steinfeld, G. \& Janiak, C. (2009). Inorg. Chem. 48, 2166-2180.
Han, Y., Fu, L., Mafra, L. \& Shi, F. N. (2012). J. Solid State Chem. 186, 165-170.

Hansson, E., Svaeren, S. E., Møller, J., Schroll, G., Leander, K. \& Swahn, C.-G. (1973). Acta Chem. Scand. 27, 823-834.

Hazen, R. M., Hummer, D. R., Hystad, G., Downs, R. T. \& Golden, J. J. (2016). Am. Mineral. 101, 889-906.

Hibbs, D. E., Kolitsch, U., Leverett, P., Sharpe, J. L. \& Williams, P. A. (2002). Mineral. Mag. 66, 459-464.

Hoskins, B. F. \& Robson, R. (1989). J. Am. Chem. Soc. 111, 5962 5964.

Huang, Y. G., Mu, B., Schoenecker, P. M., Carson, C. G., Karra, J. R., Cai, Y. \& Walton, K. S. (2011). Angew. Chem. Int. Ed. 50, 436440.

Hummer, D. R., Noll, B. C., Hazen, R. M. \& Downs, R. T. (2017). Am. Mineral. 102, 1129-1132.

Huskić, I., Christopherson, J.-C., Užarević, K. \& Friščić, T. (2016). Chem. Commun. 52, 5120-5123.

Huskić, I. \& Friščić, T. (2015). Acta Cryst. A71, S58.

Huskić, I., Pekov, I. V., Krivovichev, S. V. \& Friščić, T. (2016). Sci. $A d v .2, \mathrm{e} 1600621$

Iwamoto, T., Nishikiori, S. I., Kitazawa, T. \& Yuge, H. (1997). J. Chem. Soc. Dalton Trans. pp. 4127-4136.

Julien, P. A., Mottillo, C. \& Friščić, T. (2017). Green Chem. 19, 2729 2747.

Katsenis, A. D., Puškarić, A., Štrukil, V., Mottillo, C., Julien, P. A., Užarević, K., Pham, M. H., Do, T. O., Kimber, S. A. J., Lazić, P., Magdysyuk, O., Dinnebier, R. E., Halasz, I. \& Friščić, T. (2015). Nat. Commun. 6, 6662.

Kitagawa, S., Kitaura, R. \& Noro, S. I. (2004). Angew. Chem. Int. Ed. 43, 2334-2375.

Klop, E. A., Duisenberg, A. J. M. \& Spek, A. L. (1983). Acta Cryst. C39, 1342-1344.

Knipovich, Y. N., Komkov, A. I. \& Nefedov, E. I. (1963). Tr. Vses. Nauchno-Issled. Geol. Inst. 96, 131-135.

Krivovichev, S. V. (2013). Mineral. Mag. 77, 275-326.

Lam, C. K., Hau, S. C. K., Yau, C. W. \& Mak, T. C. W. (2016). Cryst. Growth Des. 16, 759-773.

Laniel, D., Weck, G., Gaiffe, G., Garbarino, G. \& Loubeyre, P. (2018). J. Phys. Chem. Lett. 9, 1600-1604.

Lee, C. Y., Farha, O. K., Hong, B. J., Sarjeant, A. A., Nguyen, S. T. \& Hupp, J. T. (2011). J. Am. Chem. Soc. 133, 15858-15861.

Lee, J., ong,, Farha, O. K., Roberts, J., Scheidt, K. A., Nguyen, S., inh, T. \& Hupp, J. T. (2009). Chem. Soc. Rev. 38, 1450-1459.

Leonhard, K. C. (1826). Handbuch der Oryktognosie. Heidelberg.

Li, M., Li, D., O'Keeffe, M. \& Yaghi, O. M. (2014). Chem. Rev. 114, 1343-1370.

Liang, N., Wang, J., Yuan, D., Li, B. \& Li, H. (2010). Inorg. Chem. Commun. 13, 844-846.

Liebau, F. (2003). Microporous Mesoporous Mater. 58, 15-72.

Liu, T. F., Zhang, W., Sun, W. H. \& Cao, R. (2011). Inorg. Chem. 50, $5242-5248$

Lorusso, G., Sharples, J. W., Palacios, E., Roubeau, O., Brechin, E. K., Sessoli, R., Rossin, A., Tuna, F., McInnes, E. J. L., Collison, D. \& Evangelisti, M. (2013). Adv. Mater. 25, 4653-4656.

Luz, L. L. da, Lucena Viana, B. F., da Silva, G. C. O., Gatto, C. C., Fontes, A. M., Malta, M., Weber, I. T., Rodrigues, M. O. \& Júnior, S. A. (2014). CrystEngComm, 16, 6914-6918.

Luz, L. L. da, Milani, R., Felix, J. F., Ribeiro, I. R. B., Talhavini, M., Neto, B. A. D., Chojnacki, J., Rodrigues, M. O. \& Júnior, S. A. (2015). ACS Appl. Mater. Interfaces, 7, 27115-27123.

Lysenko, A. B., Senchyk, G. A., Lincke, J., Lässig, D., Fokin, A. A., Butova, E. D., Schreiner, P. R., Krautscheid, H. \& Domasevitch, K. V. (2010). Dalton Trans. 39, 4223-4231.

Ma, H., Liu, B., Li, B., Zhang, L., Li, Y. G., Tan, H. Q., Zang, H. Y. \& Zhu, G. (2016). J. Am. Chem. Soc. 138, 5897-5903.

MacGillivray, L. R., Papaefstathiou, G. S., Friščić, T., Hamilton, T. D., Bučar, D. K., Chu, Q., Varshney, D. B. \& Georgiev, I. G. (2008). Acc. Chem. Res. 41, 280-291. 
Mączka, M., Pietraszko, A., Macalik, B. \& Hermanowicz, K. (2014). Inorg. Chem. 53, 787-794.

Martinez-Carrera, S. (1966). Acta Cryst. 20, 783-789.

Matsui, M., Watanabe, T., Kamijo, N., Lapp, R. L. \& Jacobson, R. A. (1980). J. Econ. 28-32.

Maynard-Casely, H. E., Hodyss, R., Cable, M. L., Vu, T. H. \& Rahm, M. (2016). IUCrJ, 3, 192-199.

McDonald, T. R. R. \& Spink, J. M. (1967). Acta Cryst. 23, 944949.

Meng, L., Cheng, Q., Kim, C., Gao, W. Y., Wojtas, L., Chen, Y. S., Zaworotko, M. J., Zhang, X. P. \& Ma, S. (2012). Angew. Chem. Int. Ed. 51, 10082-10085.

Mills, S. J., Hatert, F., Nickel, E. H. \& Ferraris, G. (2009). Eur. J. Mineral. 21, 1073-1080.

Miyatsu, S., Kofu, M., Nagoe, A., Yamada, T., Sadakiyo, M., Yamada, T., Kitagawa, H., Tyagi, M., García Sakai, V. \& Yamamuro, O. (2014). Phys. Chem. Chem. Phys. 16, 17295-17304.

Molčanov, K. \& Stilinović, V. (2014). Angew. Chem. Int. Ed. 53, 638652.

Moore, J. M. et al. (2016). Science, 351, 1284-1293.

Morton, A. A. (1946). The Chemistry of Heterocyclic Compounds. New York: McGraw-Hill.

Moulton, B. \& Zaworotko, M. J. (2001). Chem. Rev. 101, 16291658.

Nickel, E. H. (1995). Can. Mineral. 33, 689-690.

Niekerk, J. N. van \& Schoening, F. R. L. (1953). Acta Cryst. 6, 227232.

Öhrström, L. (2015). Crystals, 5, 154-162.

Olds, T. A., Plášil, J., Kampf, A. R., Simonetti, A., Sadergaski, L. R., Chen, Y.-S. \& Burns, P. C. (2017). Geology, 45, 1007-1010.

Ollendorff, W. \& Weigel, F. (1969). Inorg. Nucl. Chem. Lett. 5, $263-$ 269.

Papaefstathiou, G. S. \& MacGillivray, L. R. (2002). Angew. Chem. Int. Ed. 41, 2070-2073.

Park, K. S., Ni, Z., Côté, A. P., Choi, J. Y., Huang, R., Uribe-Romo, F. J., Chae, H. K., O'Keeffe, M. \& Yaghi, O. M. (2006). Proc. Natl Acad. Sci. USA, 103, 10186-10191.

Parkin, S. \& Hope, H. (1998). Acta Cryst. B54, 339-344.

Pedireddi, V. R. \& Belhekar, D. (2002). Tetrahedron, 58, 29372941.

Pekov, I. V., Chukanov, N. V., Belakovskiy, D. I., Lykova, I. S., Yapaskurt, V. O., Zubkova, N. V., Shcherbakova, E. P. \& Britvin, S. N. (2016). Mineral. Mag. 80, 199-205.

Pettersen, R. C. (1984). Nature, 310, 18.

Piro, O. E. \& Baran, E. J. (2018). Crystallogr. Rev. 24, 149-175.

Piro, O. E., Echeverría, G. A., González-Baró, A. C. \& Baran, E. J. (2016). Phys. Chem. Miner. 43, 287-300.

Plater, M. J. \& Harrison, W. T. A. (2015). J. Chem. Res. 39, 279-281.

Pointillart, F., Train, C., Gruselle, M., Villain, F., Schmalle, H. W., Talbot, D., Gredin, P., Decurtins, S. \& Verdaguer, M. (2004). Chem. Mater. 16, 832-841.

Purvis, O. W. \& Halls, C. (1996). Lichenologist, 28, 571-601.

Qi, F., Stein, R. S. \& Friščí, T. (2014). Green Chem. 16, 121-132.

Reboul, J., Furukawa, S., Horike, N., Tsotsalas, M., Hirai, K., Uehara, H., Kondo, M., Louvain, N., Sakata, O. \& Kitagawa, S. (2012). Nat. Mater. 11, 717-723.

Ringertz, H. (1965). Acta Cryst. 19, 286-287.

Ringertz, H. (1966). Acta Cryst. 20, 397-403.

Robl, C. \& Kuhs, F. W. (1991). J. Solid State Chem. 92, 101-109.

Rong-Hua, Z. \& Han-Guo, L. (2007). Acta Cryst. E63, m2925.

Rood, J. A., Noll, B. C. \& Henderson, K. W. (2006). Inorg. Chem. 45, 5521-5528.

Rosi, N. L., Eckert, J., Eddaoudi, M., Vodak, D. T., Kim, J., O'Keeffe, M. \& Yaghi, O. M. (2003). Science, 300, 1127-1129.

Rossin, A., Ienco, A., Costantino, F., Montini, T., Di Credico, B., Caporali, M., Gonsalvi, L., Fornasiero, P. \& Peruzzini, M. (2008). Cryst. Growth Des. 8, 3302-3308.
Rouse, R. C., Peacor, D. R., Essene, E. J., Coskren, T. D. \& Lauf, R. J. (2001). Geochim. Cosmochim. Acta, 65, 1101-1115.

Rungtaweevoranit, B., Diercks, C. S., Kalmutzki, M. J. \& Yaghi, O. M. (2017). Faraday Discuss. 201, 9-45.

Sadakiyo, M., Yamada, T., Honda, K., Matsui, H. \& Kitagawa, H. (2014). J. Am. Chem. Soc. 136, 7701-7707.

Sadakiyo, M., Yamada, T., Kato, K., Takata, M. \& Kitagawa, H. (2016). Chem. Sci. 7, 1349-1356.

Sadakiyo, M., Yamada, T. \& Kitagawa, H. (2009). J. Am. Chem. Soc. 131, 9906-9907.

Sattar, S., Carroll, M. J., Sargeant, A. A. \& Swift, J. A. (2008). CrystEngComm, 10, 155-157.

Savard, D., Cook, C., Enright, G. D., Korobkov, I., Burchell, T. J. \& Murugesu, M. (2011). CrystEngComm, 13, 5190-5197.

Schmidt, G. M. J. (1971). Pure Appl. Chem. 27, 647-678.

Schoedel, A., Li, M., Li, D., O'Keeffe, M. \& Yaghi, O. M. (2016). Chem. Rev. 116, 12466-12535.

Seth, S. \& Matzger, A. J. (2017). Cryst. Growth Des. 17, $4043-$ 4048.

Shan, N., Bond, A. D. \& Jones, W. (2002). Tetrahedron Lett. 43, 31013104.

Shan, N., Perry, M. L., Weyna, D. R. \& Zaworotko, M. J. (2014). Expert Opin. Drug Metab. Toxicol. 10, 1255-1271.

Shang, R., Xu, G. C., Wang, Z. M. \& Gao, S. (2014). Chem. Eur. J. 20, $1146-1158$

Sharga, O. V., Lysenko, A. B., Krautscheid, H. \& Domasevitch, K. V. (2010). Acta Cryst. C66, 269-272.

Sheberla, D., Bachman, J. C., Elias, J. S., Sun, C. J., Shao-Horn, Y. \& Dincă, M. (2017). Nat. Mater. 16, 220-224.

Sillén, L. G., Martell, A. E. \& Bjerrum, J. (1964). Stability Constants of Metal-Ion Complexes. London: Chemical Society.

Skinner, H. C. W. (2005). Mineral. Mag. 69, 621-641.

Slade, P. G., Raupach, M. \& Radoslovich, E. W. (1973). Acta Cryst. B29, 279-286.

Sone, Y. (1996). J. Electrochem. Soc. 143, 1254-1259.

Sours, R. E., Fink, D. A. \& Swift, J. A. (2002). J. Am. Chem. Soc. 124, $8630-8636$

Spanopoulos, I., Bratsos, I., Tampaxis, C., Kourtellaris, A., Tasiopoulos, A., Charalambopoulou, G., Steriotis, T. A. \& Trikalitis, P. N. (2015). CrystEngComm, 17, 532-539.

Srebrodolskii, B. I. (1975). Zap. Vses. Mineral. Oba, 104, 326328.

Steele, B. A., Stavrou, E., Crowhurst, J. C., Zaug, J. M., Prakapenka, V. B. \& Oleynik, I. I. (2017). Chem. Mater. 29, 735-741.

Steiner, T. (2002). Angew. Chem. Int. Ed. 41, 49-76.

Steinfink, H. \& Brunton, G. D. (1970). Inorg. Chem. 9, 21122115.

Storm, C. B., Krane, J., Skjetne, T., Telanes, N., Branthaver, J. F. \& Baker, E. W. (1984). Science, 223, 1075-1076.

Su, X., Kamat, S. \& Heuer, A. H. (2000). J. Mater. Sci. 35, 55455551.

Taylor, R. M. (1972). Z. Anorg. Allg. Chem. 390, 85-96.

Taylor, T. N., Hass, H., Remy, W. \& Kerp, H. (1995). Nature, 378, 244 244.

Tazzoli, V. \& Domeneghatti, C. (1980). Am. Mineral. 65, 27-334.

Titi, H. M., Tripuramallu, B. K. \& Goldberg, I. (2016). CrystEngComm, 18, 3318-3339.

Topić, F. \& Rissanen, K. (2016). J. Am. Chem. Soc. 138, 66106616.

Trask, A. V. \& Jones, W. (2005). Top. Curr. Chem. 254, 41-70.

Treibs, A. (1935). Justus Liebigs Ann. Chem. 517, 172-196.

Unger, B. (1846). Ann. Chem. Pharm. 59, 58-68.

Uribe-Romo, F. J., Hunt, J. R., Furukawa, H., Klo, C., Keeffe, M. O. \& Yaghi, O. M. (2009). J. Am. Chem. Soc. 131, 4570-4571.

Užarević, K., Wang, T. C., Moon, S. Y., Fidelli, A. M., Hupp, J. T., Farha, O. K. \& Friščić, T. (2016). Chem. Commun. 52, 2133-2136. Vaidhyanathan, R., Natarajan, S. \& Rao, C. N. R. (2001). Chem. Mater. 13, 185-191. 
Viney, C. (1999). Biorheology, 36, 319-323.

Vishweshwar, P., McMahon, J. A., Bis, J. A. \& Zaworotko, M. J. (2006). J. Pharm. Sci. 95, 499-516.

Volkringer, C., Loiseau, T., Guillou, N., Férey, G., Popov, D., Burghammer, M. \& Riekel, C. (2013). Solid State Sci. 26, 3844.

Vranova, V., Rejsek, K. \& Formanek, P. (2013). Sci. World J. 2013, 524239.

Waller, P. J., Gándara, F. \& Yaghi, O. M. (2015). Acc. Chem. Res. 48, 3053-3063.

Walton, S. A. (2001). Ann. Sci. 58, 357-379.

Wang, P., Fan, R. Q., Liu, X. R., Wang, L. Y., Yang, Y. L., Cao, W. W., Yang, B., Hasi, W., Su, Q. \& Mu, Y. (2013). CrystEngComm, 15, 1931-1949.

Wang, L., Ye, Y., Li, Z., Lin, Q., Ouyang, J., Liu, L., Zhang, Z. \& Xiang, S. (2017). Cryst. Growth Des. 17, 2081-2089.

Wells, A. F. (1977). Three-Dimensional Nets and Polyhedra. New York: Wiley.

Werner, A. G. \& Hoffmann, C. A. S. (1789). Bergmännisches J. 1, 369398.

Wöhler, F. (1828). Ann. Phys. Chem. 88, 253-256.
Xu, Y., Wang, Q., Shen, C., Lin, Q., Wang, P. \& Lu, M. (2017). Nature, 549, 78-81.

Yamada, T., Sadakiyo, M. \& Kitagawa, H. (2009). J. Am. Chem. Soc. 131, 3144-3145.

Zellelow, A. Z., Kim, K. H., Sours, R. E. \& Swift, J. A. (2010). Cryst. Growth Des. 10, 418-425.

Zhai, Q. G., Lu, C. Z., Chen, S. M., Xu, X. J. \& Yang, W. (2006). Cryst. Growth Des. 6, 1393-1398.

Zhang, Y., Bhadbhade, M., Scales, N., Karatchevtseva, I., Price, J. R., Lu, K. \& Lumpkin, G. R. (2014). J. Solid State Chem. 219, 1-8.

Zhang, J. P., Lin, Y. Y., Huang, X. C. \& Chen, X. M. (2005). J. Am. Chem. Soc. 127, 5495-5506.

Zhang, C., Sun, C., Hu, B., Yu, C. \& Lu, M. (2017). Science, 355, 374376.

Zhang, K., Xie, X., Li, H., Gao, J., Nie, L., Pan, Y., Xie, J., Tian, D., Liu, W., Fan, Q., Su, H., Huang, L. \& Huang, W. (2017). Adv. Mater. 29, 1-6.

Zhang, J. P., Zhang, Y. B., Lin, J. \& Chen, X. M. (2012). Chem. Rev. 112, 1001-1033.

Zhou, H. C., Long, J. R. \& Yaghi, O. M. (2012). Chem. Rev. 112, 673674. 